\title{
Assessment of seasonal and year-to-year surface salinity signals retrieved from SMOS and Aquarius missions in the Bay of Bengal
}

\author{
Akhil V. P. ${ }^{1,{ }^{*}}$, Lengaigne Matthieu ${ }^{2,3,5}$, Durand Fabien ${ }^{1}$, Vialard Jerome ${ }^{3,5}$, Chaitanya A. V. S. ${ }^{4}$, \\ Keerthi M. G. ${ }^{2}$, Gopalakrishna V. V. ${ }^{4}$, Boutin Jacqueline ${ }^{3,5}$, De Boyer Montegut Clement
}

${ }^{1}$ IRD, LEGOS, Toulouse, France.

${ }^{2}$ NIO, Indofrench Cell Water Sci, IISc NIO IITM IRD Joint Int Lab, Panaji, Goa, India.

${ }^{3}$ Univ Paris 06, Univ Paris 04, LOCEAN IPSL, CNRS IRD MNHN, Paris, France.

${ }^{4} \mathrm{NIO}$, Panaji, Goa, India.

${ }^{5}$ IFREMER, LOS, Plouzane, France.

*Corresponding author : V. P. Akhil, email address : akhil1585@gmail.com

\begin{abstract}
:
The Bay of Bengal (BoB) exhibits a wide range of sea surface salinity (SSS), with very fresh water induced by heavy monsoonal precipitation and river run-offs to the north, and saltier water to the south. This is a particularly challenging region for the application of satellite-derived SSS measurements because of the potential pollution of the SSS signal by radio frequency interference (RFI) and landinduced contamination in this semi-enclosed basin. The present study validates recent level-3 monthly gridded $\left(1^{\circ} \times 1^{\circ}\right)$ SSS products from Soil Moisture and Ocean Salinity (SMOS) and Aquarius missions to an exhaustive in situ SSS product for the BoB. Current SMOS SSS retrievals do not perform better than existing climatologies. This is in stark contrast to Aquarius, which outperforms SMOS and available SSS climatologies everywhere in the BoB. While SMOS only captures the SSS seasonal evolution in the northern part of the Bay, Aquarius accurately captures the seasonal signal in the entire basin. The Aquarius product is also able to capture SSS non-seasonal anomalies, with an approximate correlation (r) of 0.75 with box-averaged in situ data in the northern, central, and western parts of the Bay. Aquarius can, thus, be confidently used to monitor large-scale year-to-year SSS variations in the BoB.
\end{abstract}




\section{Introduction}

46

The Bay of Bengal (BoB) stands out as a very peculiar region for salinity distribution in the tropical belt. The strong summer monsoon oceanic rainfall and continental runoffs into this relatively small and semi-enclosed basin result in an intense dilution of the seawater in northern part of the Bay, therefore inducing some of the lowest sea surface salinity (SSS) in the tropical belt (Figure 1). The resulting very strong near-surface salinity vertical stratification is believed to play a key role in the regional climate (Shenoi et al. 2002, Neetu et al. 2012). Indeed, the enhancement of near-surface ocean stability by salinity stratification reduces turbulent entrainment of cooler thermocline water into the mixed layer and consequently maintains high sea surface temperatures in the BoB (Shenoi et al. 2002). The stronger BoB salinity stratification after the monsoon may also favour intense cyclones during that season, by inhibiting oceanic vertical mixing and surface cooling along the cyclone track, and hence leading to enhanced evaporation that can sustain the cyclone (Neetu et al. 2012 and references therein). Last but not least, salinity could also act as a marker of changes in the water cycle associated with anthropogenic forcing (e.g. Terray et al. 2012).

Because of the potentially important role of salinity in the climate dynamics of this region, several studies already investigated the seasonal BoB SSS variations by building salinity climatologies derived from available hydrographic data (e.g. Rao and Sivakumar. 2003, Chatterjee et al. 2012, Zweng et al. 2013), These climatologies reveal a strong freshening in the northeastern part of the Bay during summer in response to the freshwater input associated with monsoonal rainfall and Ganges-Brahmaputra river discharge (Figure 1a). This freshwater pool further strengthens and expands southward along the eastern and western boundaries of the Bay in fall (Figure 1b). It then weakens during winter (Figure 1c) 
and retreats back to the northeasternmost part of the Bay during spring (Figure $1 d$ ). While these climatologies are not able to capture the fine spatial scale of this coastal freshening (Chaitanya et al. 2014a), the coverage of in situ data used in these products is sufficient to capture the main large-scale SSS seasonal features in the Bay (Chatterjee et al. 2012). The monitoring of the year-to-year SSS variability is however generally far more challenging due to the insufficient spatio-temporal sampling by the in situ network (Vinayachandran and Nanjundiah 2009, Chaitanya et al. 2014b).

The advent of satellite salinity measurements provides a unique opportunity to improve the monitoring of SSS variations in this climatically relevant region. The Soil Moisture and Ocean Salinity (SMOS) European mission (Mecklenburg et al. 2008) launched in November 2009 and the Argentina/US Aquarius mission (Lagerloef et al. 2008) from June 2011 to June 2015 both provide global SSS estimates. These new spaceborne SSS measurements have been routinely validated, with global root-mean-square errors around 0.2 practical salinity scale (pss) for monthly Aquarius SSS fields around $150 \mathrm{~km} \times 150 \mathrm{~km}$ global grid (Lagerloef et al. 2013) and for 10-days SMOS averages around $100 \mathrm{~km} \times 100 \mathrm{~km}$ grid in the tropical regions (Boutin et al. 2012). Recent research has demonstrated the value of these satellite missions in capturing open-ocean signals related to large-scale climate modes such as La Niña signature in the tropical Pacific (Hasson et al. 2014), the Indian Ocean Dipole signature in the eastern part of the equatorial Indian Ocean (Durand et al. 2013) or planetary waves signature in the Southern Indian Ocean (Menezes et al. 2014). The assimilation of Aquarius SSS also improves the simulation of the equatorial Wyrkti jets in the Indian Ocean (Chakraborty et al. 2014).

Whether these satellite data can accurately capture SSS variations in relatively small basins surrounded by continental masses however remains unclear. Near-coastal environments are indeed particularly challenging for the application of satellite-derived SSS 
measurements because radio frequency interferences (RFI) linked to artificial sources (e.g. radars that emit in the frequency band of the instruments) and land-induced contamination on antenna side lobes (Reul et al. 2012, Subrahmanyam et al. 2013) can obscure climatically relevant signals. A recent study (Gierach et al. 2013) however demonstrated the ability of both Aquarius and SMOS to monitor SSS variations in the Gulf of Mexico, offering promises for monitoring SSS evolution in a near-coastal environment.

The BoB, approximately 1000-2000 km wide semi-enclosed basin similar to the Gulf of Mexico, is also very challenging for SSS satellite retrievals. A thorough validation of the SSS remotely-sensed products is therefore a pre-requisite before using these data to describe and understand the SSS evolution in this region. Preliminary analyses reported major issues in the satellites ability to retrieve SSS there. Subrahmanyam et al. (2013) and Ratheesh et al. (2013) indeed reported an erratic behaviour of an earlier version of the level-3 SMOS dataset used in the current study for that region for the year 2010, with weak and insignificant spatial correlations, and attributed this behaviour to RFI and land contamination. Similarly, analyses performed by Ratheesh et al. (2014) for level-3 Aquarius dataset over the entire Indian Ocean region from August 2011 to December 2012 reported a 0.5 pss overestimation and a poor agreement with observations for SSS values lower than 32 pss, which are typical of the northern part of the BoB.

While the above analyses revealed a poor accuracy of the preliminary satellite retrievals of the Bay of Bengal SSS, recent evolutions such as an improved roughness correction for Aquarius (Yueh et al. 2014) and an improved handling of RFI contamination for SMOS (Reul et al. 2014) are now available for the most recent SSS products derived from the satellites microwave measurements. In addition, both missions have now accumulated about three years of data, allowing a qualitative assessment of the ability of each satellite to capture the seasonal and year-to-year SSS evolution in this region. The goal of the present 
study is therefore to provide an in-depth, up-to-date assessment of the ability of both satellites

121 to monitor the seasonal and year-to-year SSS variations in the BoB. This will be done by

122 splitting the basin into various sub-regions and by comparing remotely-sensed SSS to a

123 comprehensive dataset compiling all in situ observations available during the recent period

124 (Chaitanya et al. 2014b). This paper will focus on the validation of the most recent versions

125 (at the time of writing) of monthly level-3 products for both missions. Due to the larger

126 number of measurements used to compute the SSS pixel-average, these monthly resolution

127 products are indeed expected to exhibit a better accuracy compared to products derived at a

128 higher temporal resolution from the same data and methods (Hernandez et al. 2014).

129 2. Datasets and methods

130

This section describes the two satellite SSS products (Sections 2.1 and 2.2), the in situ dataset (Sections 2.3) used in the present study and discusses the co-location method used to compare in situ and remotely sensed data (Section 2.4).

\subsection{SMOS level-3 data}

SMOS is a polar orbiting satellite with a passive microwave sensor operating within

137 the L-Band (at 1.404-1.423 GHz), operated as part of European Space Agency (ESA)'s 138 Living Planet Programme (McMullan et al. 2008, Mecklenburg et al. 2012). SMOS was 139 launched on 2 November 2009, making it the first satellite to provide continuous multi140 angular L-band radiometric measurements over the globe. It is based on 69 individual 141 radiometers that are used to retrieve the SSS field through polarimetric interferometry (see 142 Kerr et al. 2010, Reul et al. 2012, 2013, and references therein for further details on the 143 measurement technique). Due to the interferometry principle and the antenna shape, the field 144 of view is $1200 \mathrm{~km}$ wide and a global coverage is achieved every three days. 
146 SSS products, have a spatial resolution of $43 \mathrm{~km}$ but a rather low accuracy of 0.6 to 1.7 pss

147 (Reul et al. 2012, Boutin et al. 2012). After averaging these measurements over one month,

$148100 \mathrm{~km}$, and after removing large-scale biases, the level-2 version 5 processor provided by

149 CATDS/LOCEAN expertise center (available at www.catds.fr) achieve an accuracy of 0.2-0.3

150 pss in subtropical regions free of RFIs (Hernandez et al. 2014, Hasson et al. 2014).

151 Unfortunately, the procedure of outliers and RFI sorting used in this dataset flags almost all

152 the SMOS measurements in the $\mathrm{BoB}$ as bad data. Hence, in this study, we use the $1^{\circ} \times 1^{\circ}$

153 gridded monthly SSS composites from the V02 version of the SMOS level-3 research product

154 generated by the CATDS/Ifremer expertise center (also available at www.catds.fr). With

155 respect to the ESA level 2 processing, it includes an improved RFI mitigation and a $5^{\circ} \times 5^{\circ}$

156 adjustment to the World Ocean Atlas SSS climatology of Antonov et al. (2010) to remove

157 residual temporal drifts and land contamination in SMOS brightness temperature level 1

158 products (Reul et al. 2014). This SSS bias mitigation and the improved RFI handling enhance

159 the data quality close to the coast compared to other level-3 products (Zhang et al. 2013).

160 Data of the first four months of 2010 were not reprocessed because of reduced data

161 quality during that period. This product therefore covers the May 2010-December 2013

162 period. As shown on Figure $2 a$, this product has few missing values throughout the central

163 and southern Bay. The percentage of valid data however drops considerably in the

164 northeastern part of the basin near the Ganges-Brahmaputra river mouth, with any SSS

165 retrieval north of $20^{\circ} \mathrm{N}$. This drop largely results from brightness temperature data flagged as 166 outliers (not shown). 


\subsection{Aquarius level 3 data}

Aquarius is NASA's Earth orbiting mission launched on 10 June 2011. The Aquarius instrument measures the brightness temperature of the sea surface within the L-band (1.400$1.427 \mathrm{GHz}$ ) with three separate radiometers and the surface roughness with an active scatterometer operating at $1.2 \mathrm{GHz}$. These data, in combination with concurrent SST, and other auxiliary data, are used to estimate SSS. The resolution of individual SSS measurements is $100-150 \mathrm{~km}$ and a global coverage of the ocean is obtained after about 7 days. After four years of successful data collection this mission ended on 7 June 2015 due to an unrecoverable hardware failure.

This study uses the CAPv3 Aquarius level $-31^{\circ} \times 1^{\circ}$ monthly composites. This product combines the measurements from the three radiometers and the scatterometer using the Combined Active-Passive Algorithm applied to version 3.0 of the Aquarius/SAC-D data updated in July 2014 (available at ftp:/podaacftp.jpl.nasa.gov/allData/aquarius/L3/mapped/CAPv3). This algorithm computes SSS by minimizing the least squares error between measurements and model functions of brightness temperatures and radar backscatter. It also includes a rain-corrected salinity based on collocated SSMI/S and WindSAT data. This rain correction algorithm has been established assuming that the freshwater inputs are homogeneously spread over the first $5 \mathrm{~m}$ and hence, in case of rain-induced surface fresh cells, it is expected to overestimate the SSS (Tang et al. 2014).

This product covers the August 2011 - June 2014 period. Like SMOS (Figure 2a), Aquarius exhibits few missing data south of $15^{\circ} \mathrm{N}$ (Figure $2 b$ ). However, Aquarius offers a better spatial coverage in the northernmost part of the basin as compared to SMOS, because there is no far-reaching RFI issue for Aquarius whose antenna lobes are much narrower than for SMOS, due to the interferometry technique used for the SMOS instrument. 


\subsection{North Indian Ocean Atlas climatology} al. (2012) and shown in Figure 1 is used to qualitatively validate the SSS seasonal cycle from the satellite data. This $1^{\circ} \times 1^{\circ}$ monthly climatology includes all the data from the World Ocean Database 2009 (WOD09) (Locarnini et al. 2010, Antonov et al. 2010), complemented with Conductivity-Temperature-Depth (CTD) stations from Indian oceanographic cruises. The inclusion of the Indian oceanographic cruises database in NIOA considerably improves the data coverage in the periphery of the BoB compared with WOD09, especially along its western boundary (Chatterjee et al. 2012). Year-to-year SSS anomalies from both satellite datasets and in situ products detailed below are calculated by subtracting this NIOA climatology from their raw values.

\subsection{Blended in situ dataset}

\subsubsection{Data sources}

Comparisons with a recent in situ dataset directly derived from the one presented in

216 Chaitanya et al. (2014b) will allow a quantitative validation of the satellites retrieval. This 217 dataset compiles all the available in situ SSS measurements over the BoB from December 2182008 to June 2014. It gathers six different salinity data sources: Array for Real-Time 219 Geostrophic Oceanography (Argo) profilers (Roemmich et al. 2009), ship-of-opportunity 220 eXpendable Conductivity-Temperature-Depth (XCTD) profiles and bucket measurements

221 (Chaitanya et al. 2014a), Research Moored Array for African-Asian-Australian Monsoon 222 Analysis and Prediction (RAMA) moorings (McPhaden et al. 2009), Ocean Moored buoy 
223 Network for Northern Indian Ocean (OMNI) moorings (Venkatesan et. al. 2013), ship-of-

224 opportunity thermosalinograph transects (Alory et al., 2015) and dedicated hydrographic 225 cruises. Argo profiles are the main contributor to this SSS product. Considering the 226 uppermost valid measurements within the $5 \mathrm{~m}$ to $15 \mathrm{~m}$ layer, typically located at around $8 \mathrm{~m}$ 227 depth, there are more than 10000 valid salinity measurements over the 2009-2014 period. 228 This in situ dataset also includes 1200 valid measurements at about $1 \mathrm{~m}$ depth from bucket 229 samples and at about $5 \mathrm{~m}$ depth from XCTD salinity measurements collected on an 230 approximately bimonthly basis along two repeated merchant ship tracks between Chennai 231 (label ' $\mathrm{C}$ ' in Figure $2 c, d$ ) and Port Blair (label 'PB '), and between Kolkata (label ' $\mathrm{K}$ ') and 232 Port Blair. In addition, our dataset comprises point-wise salinity measurements at $1 \mathrm{~m}$ depth 233 over the $2009-2014$ period from three RAMA moorings $\left(90^{\circ} \mathrm{E}-8^{\circ} \mathrm{N} ; 90^{\circ} \mathrm{E}-12^{\circ} \mathrm{N}\right.$ and $90^{\circ} \mathrm{E}-$ $23415^{\circ} \mathrm{N}$; circles on Figure $\left.2 c, d\right)$ and at $5 \mathrm{~m}$ depth from six OMNI moorings $\left(86^{\circ} \mathrm{E}-11^{\circ} \mathrm{N}, 85^{\circ} \mathrm{E}-\right.$ $2358^{\circ} \mathrm{N}, 83^{\circ} \mathrm{E}-14^{\circ} \mathrm{N}, 88^{\circ} \mathrm{E}-16^{\circ} \mathrm{N}, 94^{\circ} \mathrm{E}-10^{\circ} \mathrm{N}, 89^{\circ} \mathrm{E}-18^{\circ} \mathrm{N}$; triangles on Figure $2 c, d$ ). Finally, this 236 dataset also includes salinity measurements representative of the 0-10 $\mathrm{m}$ upper ocean layer 237 derived from a thermosalinograph on-board a merchant ship (M/S Lavender) crossing the 238 southern Bay every 3-4 months during the October 2008 to October 2012 period (dotted line 239 in Figure $2 c, d$ ) and a few 0-10 m depth measurements from shipborne CTD casts in the 240 coastal western Bay provided by the National Institute of Oceanography Data Centre (India).

\section{$242 \quad$ 2.4.2. Colocation method}

In a similar way to Chaitanya et al. (2014b), these six data sources were merged into a

245 single dataset by computing the median of all available individual measurements (irrespective

246 of their nature: autonomous profiler, mooring, underway ship measurements), at the spatial 247 and temporal resolution of the satellite products $\left(1^{\circ} \times 1^{\circ} \times 1\right.$ month $)$. 

which are offset by $0.5^{\circ}$ both in latitude and in longitude, resulting in two versions of our gridded product. The main difference with the original in situ product presented in Chaitanya et al. (2014b) is the temporal resolution: while Chaitanya et al. (2014b) used a product with a 2523 months temporal resolution, the present study uses a monthly resolution to allow a 253 validation of the both satellites level-3 monthly products.

Figure $2 c, d$ illustrates the data density of the in situ data, collocated with each of the remotely-sensed SSS products. The in situ validation data density is rather heterogeneous, with a reasonably good sampling over most of the central part of the Bay but sparser data in 257 near-coastal regions. This analysis also reveals that the Andaman Sea (east of $93^{\circ} \mathrm{E}$ and south 258 of $15^{\circ} \mathrm{N}$ ) is practically devoid of in situ observations, preventing an assessment of the 259 remotely sensed SSS products there. In the following, a detailed description of the SSS variability in the BoB will be

261 inferred by dividing the domain into four coherent sub-regions outlined on Figure $2 e, f$. The 262 first sub-region covers the northern part of the basin $\left(\mathrm{NBoB}, 86^{\circ} \mathrm{E}-94^{\circ} \mathrm{E} ; 16^{\circ} \mathrm{N}-23^{\circ} \mathrm{N}\right)$ where 263 the largest SSS fluctuations are found, due to both the proximity of the Ganges-Brahmaputra 264 river mouths and monsoonal precipitation (Rao and Sivakumar 2003, Akhil et al. 2014). The 265 second sub-region is located in the western part of the Bay $\left(\mathrm{WBoB}, 80^{\circ} \mathrm{E}-84^{\circ} \mathrm{E} ; 6^{\circ} \mathrm{N}-16^{\circ} \mathrm{N}\right)$ 266 and encompasses the coastal region through which the NBoB freshening is transported 267 southward during winter as a fresh tongue hugging the eastern Indian coastline (Chaitanya et 268 al. 2014a, Akhil et al. 2014). A third sub-region is located in the central $\mathrm{BoB}\left(\mathrm{CBoB}, 84^{\circ} \mathrm{E}-\right.$ $26994^{\circ} \mathrm{E} ; 6^{\circ} \mathrm{N}-16^{\circ} \mathrm{N}$ ), where the SSS variability is known to be weaker. Finally, a fourth sub270 domain is considered in the Andaman Sea $\left(94^{\circ} \mathrm{E}-99^{\circ} \mathrm{E} ; 6^{\circ} \mathrm{N}-18^{\circ} \mathrm{N}\right)$, where the variability 271 derived from satellite products is about as strong as in the northern part of the basin (Figure $2722 e, f$ ) but cannot be validated due to the lack of in situ observations (Figure $2 c, d$ ). We will 
273 compare the remotely-sensed SSS to in situ data on their $1^{\circ} \times 1^{\circ}$ monthly native grids, but also

274 from averages over the boxes above. This spatial averaging has the advantage of smoothing

275 out representation error of the in situ data, potential noise in the satellite retrievals, and to

276 focus the comparison with in situ data on large-scale features.

\subsubsection{Estimation of the accuracy of the in situ gridded SSS product}

As our SSS gridded products will serve as references for the SMOS and Aquarius

validation, this subsection provides a discussion of the accuracy of this new observational dataset. Subrahmanyam et al. (2013) reported that the instrumental error of ARGO is lower than 0.01 pss. This is also the typical instrumental accuracy of bucket measurements, RAMA moorings and thermosalinograph transects. This instrumental error is completely negligible compared with the representation error (i.e. the error on the $1^{\circ} \times 1^{\circ} \times 1$ month average SSS estimate due to an incomplete sampling of this spatio-temporal domain, Delcroix et al., 2005) and will not be further discussed.

Argo, CTD and thermosalinograph salinity measurements used in our in situ reference datasets are not collected right at the surface, but are rather representative of the 5-10 $\mathrm{m}$ depth layer. Owing to the strong haline stratification, especially in the northern Bay of Bengal, there may be an error on the surface salinity estimate resulting from this deeper measurement depth. This error can be estimated from the data provided by the three RAMA moorings at $90^{\circ} \mathrm{E} 15^{\circ} \mathrm{N}, 90^{\circ} \mathrm{E} 12^{\circ} \mathrm{N}$ and $90^{\circ} \mathrm{E} 8^{\circ} \mathrm{N}$. These moorings indeed provide simultaneous daily salinity measurements at $1 \mathrm{~m}$ and $10 \mathrm{~m}$ depth for one to two years, depending on the site. The scatterplot between those $1 \mathrm{~m}$ and $10 \mathrm{~m}$ depth salinity measurements on Figure 3 highlights

297 the very good coherency between the variability inferred from these two depths, with a 298 correlation exceeding 0.97 at the three moorings location. As expected, the salinity at $10 \mathrm{~m}$ (a 
typical sampling depth for the nearest measurement to the surface for Argo profiles) is on average saltier by 0.06 pss than the $1 \mathrm{~m}$ salinity at the northernmost mooring. This mean difference is negligible at the two moorings further south, where the stratification is not as strong as in the northern BoB. The larger mean bias (0.06 pss) and slightly weaker correlation (0.97) between $1 \mathrm{~m}$ and $10 \mathrm{~m}$ measurements at the northernmost mooring results in a larger 304 root mean square error (RMSE) there ( 0.19 pss) as compared to the other moorings further south (around $0.07 \mathrm{pss}$ ). A 0.2 pss RMSE is about ten times smaller than the SSS variations in our in situ blended product (STD of 2.14 pss). We will also see in Section 3 that this error is four times weaker than the typical RMSE of the SMOS or Aquarius products. This suggests that the varying depth of salinity data collection will not heavily affect our assessment of the satellite SSS products.

SSS in the BoB varies a lot both spatially (filaments generated by the stirring from meso-scale eddies, localized rain...) and temporally, with large SSS changes over short periods and/or short space scales (Benshila et al., 2014, and references therein). Most $1^{\circ} \times 1^{\circ}$ $\times 1$ month reduced SSS estimates from our blended product only use 1 to 10 individual 314 observations, with a median of 2 (not shown). The median of such a small number of point315 wise observations may not be representative of the actual monthly mean SSS in the $1^{\circ} \times 1^{\circ}$ pixel. Figure 4 provides an estimate of this representation error. We took advantage of the relatively large number of daily observations at RAMA moorings (about 30 per month), in 318 order to estimate the impact of the number of available observations on the accuracy of the 319 estimate of the monthly $1^{\circ} \times 1^{\circ} \mathrm{SSS}$ average. The underlying hypothesis is that the 30 daily320 sample average of RAMA is representative of the $1^{\circ} \times 1^{\circ} \times 1$ month pixel. We perform a 321 random subsampling of $N$ daily $1 \mathrm{~m}$ salinity measurements from RAMA moorings each 322 month, with $N$ ranging from 1 to 15 . We repeat this random subsampling 1000 times: figure 4 
323 shows the RMSE and correlation of the subsampled estimate against the actual monthly value,

324 as a function of the number of available observations $N$.

For the three moorings, the correlation exceeds 0.95 and RMSE is lower than 0.1 pss

327 if more than 10 observations are available. As expected, this correlation decreases and the

328 RMSE increases as the number of available observations decreases. The median value of the 329 number of observations in each $1^{\circ} \times 1^{\circ} \times 1$ month cell in our reference in situ dataset is 2 .

330 This results in a correlation of about 0.92 and RMSE about 0.18 pss for the moorings located

331 in the central and southern part of the basin, and 0.84 / 0.3 pss for the northernmost mooring.

332 We can therefore consider a root mean square representation error of 0.3 pss for our-in situ

333 dataset. As a result, the assessment of SMOS and AQUARIUS datasets will only be possible 334 up to this level of accuracy. This 0.3 pss value is however still far lower than the SSS 335 variations in our gridded in situ and we will see that it is less than half of the estimated RMSE 336 of individual pixels from satellite products. As mentioned earlier, we will also compare our in 337 situ dataset with satellite data over larger boxes to further reduce the impact of this 338 representation error.

\section{General evaluation of the remotely-sensed SSS products}

341 Figure 5 can be inserted here

342 Figure $5 a, b$ provides a synthetic view of the consistency between the $1^{\circ} \times 1^{\circ}$ monthly remotely-sensed SSS estimates and the in situ reference product. These panels illustrate that

344 the phase agreement with in situ dataset is generally better for Aquarius ( 0.82 correlation) as 345 compared to SMOS dataset (0.69 correlation). In addition, Aquarius does not exhibit any 346 significant basin-scale SSS bias (0.01 pss), while SMOS generally underestimates the SSS in 347 the BoB (-0.22 pss). The SMOS and Aquarius estimated RMSE (approximately 0.9 pss) 348 largely exceeds the uncertainties derived for the in situ product (0.1-0.2 pss attributable to the 
349 different sampling depth and 0.2-0.3 pss for the spatio-temporal representation error). Rather 350 surprisingly, Aquarius however exhibits the same RMSE as SMOS (around 0.88 pss). Those 351 statistics are however computed over different subset of the whole in situ dataset, due to the 352 different periods, grids and missing data areas of the two satellite products. We thus re353 computed the above statistics for the same sample (i.e. common pixels for the SMOS, 354 Aquarius and reference in situ product; numbers in brackets on Figure $5 a, b$ ) to allow a fair comparison between the two satellite products. This reveals that Aquarius outperforms SMOS retrieval for all considered statistics. The Aquarius RMSE, in particular, is 0.68 pss and smaller than SMOS (0.89 pss) when considering the sample common to the three products. This sensitivity of Aquarius RMSE to the collocation method (0.68 pss for the common sample and 0.88 pss for the in situ - Aquarius collocated data) arises from the extended 360 Aquarius coverage that allows retrieving SSS in the northern part of Bay, which is not the case for the SMOS product (Figure 2a,b). The northern Bay of Bengal displays an intense

362 fine-scale and high-frequency SSS variability due to stirring of intense SSS gradients by 363 meso-scale eddies (Benshila et al., 2014, and references therein). The relatively large RMSE 364 of Aquarius in the Northern BoB is thus likely related to the Aquarius / in situ validation 365 dataset inability to properly capture small-scale variability in this region (illustrated by the 366 larger scatter between Aquarius and in situ data for low SSS values, Figure 5b). A closer look 367 at Figure $5 a, b$ also reveals that the satellites performance strongly varies depending on the 368 SSS value. While Aquarius does not show any significant bias for SSS ranging from 34 to 31 369 pss, SMOS is generally fresher than the reference product for SSS higher than 33 pss and 370 saltier for SSS lower than 33 pss. The scatter of both satellites around the reference value is 371 also particularly large for the $\mathrm{NBoB}$ box (blue dots on Figure $5 a, b$ ) compared to the other 372 regions. 
374 features sampled by in situ observations but not by the satellite products may account for 375 some of the inconsistencies between in situ and satellite measurements, as discussed in 376 previous section. Comparing spatial averages of these three datasets over the large boxes 377 presented in Section 2.4 allows to smooth out a large part of small scale SSS variations in the 378 in situ datasets and noise in the satellite data retrieval and therefore to assess the impact of 379 small spatial scale and high frequency features on our SSS validation. The results are 380 presented on Figure $5 c, d$. Both SMOS and Aquarius correlations increase by about 0.1 when 381 considering box-averaged values rather than pixel-wise. The RMSE reduction is however 382 larger for Aquarius (from 0.88 pss to $0.49 \mathrm{pss}$ ) than for SMOS (from 0.88 pss to 0.63 pss).

383 This larger error reduction in Aquarius suggests that part of the mismatch between Aquarius 384 and in situ data is attributable to small-scale spatial noise smoothed out when averaging over 385 a large box (typically $1000 \mathrm{~km}$ wide) while a larger part of the SMOS retrieval error has probably a broader spatial scale, and hence cannot be reduced by spatial averaging.

Figure 6 further provides a synthetic assessment of the ability of both satellites to retrieve the $\mathrm{SSS}$ in the $\mathrm{NBoB}, \mathrm{WBoB}$ and $\mathrm{CBoB}$ sub-regions. It features the bias, correlation and RMSE between box-averaged satellite and in situ values. As far as the mean state is concerned, SMOS retrievals exhibit a systematic fresh bias everywhere in the Bay (Figure $3926 a$ ), ranging from -0.19 pss in WBoB to -0.35 pss in NBoB. This result is opposite to Reul et 393 al. (2012) and Ratheesh et al. (2013) who both reported a salty bias of SMOS retrievals over 394 the Bay over the year 2010. In contrast, Aquarius exhibits a bias weaker than 0.1 pss in $\mathrm{CBoB}$ and $\mathrm{WBoB}$ and a fresh bias of -0.26 pss in $\mathrm{NBoB}$ (Figure $6 a$ ). The phase agreement is also considerably better for Aquarius than for SMOS in all sub-regions: Aquarius correlations 397 range from 0.79 in $\mathrm{WBoB}$ to 0.94 in $\mathrm{NBoB}$ while SMOS correlations are considerably 
weaker, ranging from 0.24 in $\mathrm{WBoB}$ to 0.69 in $\mathrm{NBoB}$ (Figure $6 b$ ). Aquarius also outperforms SMOS in all BoB sub-regions when considering the RMSE statistics (Figure 6c).

The above analyses show that Aquarius outperforms SMOS for all statistics and all sub-regions of the BoB. SMOS appears to be particularly poor in retrieving the SSS variability in the central and western part of the $\mathrm{BoB}$ (correlations inferior to 0.4) while Aquarius performs satisfactorily over the entire $\mathrm{BoB}$ (correlations of order or larger than 0.8). The SSS variability in each sub-region can arise either from seasonal variations or from departures from the climatological seasonal cycle. The next two sections provide a validation of both satellites at these two timescales.

\section{Evaluation of SSS seasonal evolution}

Figure 7 displays the NIOA quarterly climatology, along with the corresponding climatology derived from SMOS and Aquarius. Of course, the three products are not expected to be strictly comparable, because SMOS and Aquarius measurements cover a much shorter period than those gathered in the NIOA. This figure hence only provides a qualitative assessment of the remotely-sensed SSS spatial distribution. A more quantitative validation of the seasonal SSS evolution of satellite data against in situ measurements will be presented in Figure 8.

As already mentioned in the introduction, there is a strong contrast between fresh waters to the northeast and saltier waters in the southwestern part during the monsoon (Figure 7a). Highest SSS values (>34 pss) are found near the southern tip of Sri Lanka while freshest waters ( $<31$ pss) hug the vicinity of the Ganges-Brahmaputra estuary. Following the summer monsoon withdrawal (Figure 7b), these northernmost waters further freshen below 30 pss and expand along both western and eastern boundaries. Finally, the eastern and western freshwater tongues gradually erode during winter and spring (Figure $7 c, d$ ). SMOS and 
424 Aquarius data qualitatively capture this basin-scale seasonal evolution (Figure $7 e$ to $7 l$ ).

425 However, some differences between satellite and in situ climatologies can be already noticed:

426 SMOS SSS are fresher than NIOA in the WBoB in summer (Figure 7a,e) and Aquarius SSS

427 are fresher than NIOA in the NBoB in fall (Figure $7 b, j$ ). Large differences can also be found

428 for both satellites in the Andaman Sea but the quality of NIOA climatology there is likely to

429 be strongly hampered by the lack of in situ observations in this region.

Figure 8 further provides a quantitative assessment of the SSS seasonal cycle from the satellites retrieval in the three sub-regions considered $(\mathrm{NBoB}, \mathrm{CBoB}$ and $\mathrm{WBoB})$ by comparing them to their collocated in situ dataset. First of all, the seasonal evolution of SSS

434 in the three selected boxes from the collocated in situ datasets (black lines on Figure 8) agrees 435 reasonably well with the one derived from the NIOA box average (blue lines on Figure 8), with correlation larger than 0.8 . This suggests that the in situ dataset captures the main 437 features of the climatological seasonal cycle depicted by the NIOA dataset despite the limited 438 number of years (around three) and the rather heterogeneous spatial coverage of this in situ 439 dataset (Figure $2 c, d)$,

440 In the northern part of the Bay, a 1.5 pss freshening is observed between July and 441 October (black line on Figure $8 a, b$ ) in response to the huge fresh water flux from monsoonal 442 rainfall and Ganges-Brahmaputra river discharge. This freshening is followed by a gradual 443 saltening from November onward. The observed freshening is larger for the in situ dataset 444 collocated with Aquarius (Figure 8b) than for the one of SMOS (Figure $8 a$ ) due to the 445 extended Aquarius data coverage in the northeasternmost part of the Bay (Figure 2a,b) where 446 the lowest salinities are found. Both satellite retrievals are able to capture this strong seasonal 447 freshening reasonably well but overestimate the freshening signal during the post-monsoon 448 season (red and black lines on Figure $8 a, b$ ). The phase agreement of Aquarius with the in situ 
449 dataset is however better than the one derived from SMOS, with correlations of 0.95 and 0.81

450 respectively.

451 The WBoB SSS also displays a seasonal freshening similar to that of NBoB but 452 occurring with a two month delay (Figure $8 c, d$ ), corresponding to the time it takes for the 453 fresh waters in the Northern Bay to be advected southward by the East India Coastal Current 454 along the western boundary (Chaitanya et al. 2014a, Benshila et al. 2014, Akhil et al. 2014). 455 The observed freshening in $\mathrm{WBoB}$ is also larger for the in situ dataset collocated with 456 Aquarius (Figure 8d) than for the one of SMOS (Figure 8c). While Aquarius reproduces the 457 seasonal timing of this coastal freshening very accurately (0.9 correlation), SMOS displays a 458 too early seasonal freshening starting in June, with several spurious peaks, resulting in a poor 459 phasing with in situ observations ( 0.27 correlation).

460 Finally, the SSS seasonal cycle in CBoB exhibits a semi-annual signal with two 461 salinity minima occurring during fall and spring (Figure $8 e, f$ ). As for WBoB, Aquarius 462 captures very accurately these seasonal variations (0.92 correlation; Figure $8 f$ ) while SMOS 463 displays an erratic behaviour and is unable to retrieve this seasonal evolution $(0.25$ 464 correlation; Figure 8e).

465 This validation shows that Aquarius reproduces the observed SSS seasonal cycle well 466 in both near-coastal and open-ocean regions. In contrast, SMOS is unable to capture the 467 seasonal variability south of $16^{\circ} \mathrm{N}$, neither in the coastal region along the west coast of India 468 nor in the central part of the Bay.

\section{Evaluation of SSS year-to-year variations}

As existing in situ climatologies such as NIOA already provide a reasonable

473 description of SSS seasonal variations, a considerable added value of satellite products is their 474 potential to describe SSS departures from the mean seasonal cycle. In order to qualitatively 
assess the satellites skill in capturing non-seasonal SSS anomalies, Figure 9 displays a

476 scatterplot of each satellite SSS estimates deviations from the NIOA climatology against

477 those from the in situ reference product. A good agreement between satellite estimates and in

478 situ data seasonal anomalies would result in a cloud of points aligned along the $x=y$ axis

479 while a strong underestimation of the non-seasonal variability of the satellite SSS estimates

480 would result in a cloud of points aligned along the $y=0$ axis. Figure $9 a$ and $9 c$ reveal that

481 SMOS retrieval considerably underestimates the observed non-seasonal variations and

482 exhibits a poor phase agreement with in situ observations for both pixel-wise and box-

483 averaged comparisons (0.36 and 0.29 correlation, respectively). In contrast with SMOS,

484 Aquarius reasonably captures the amplitude and phase of the observed SSS seasonal

485 anomalies (0.57 and 0.73 correlation for pixel-wise and box-averaged comparison

486 respectively, Figure $9 b, d$ ) and may therefore provide additional valuable information with

487 respect to the information already contained in the existing climatologies.

A more detailed analysis on the ability of the satellites retrieval to capture the temporal evolution in the three boxes where in situ data are available $(\mathrm{NBoB}, \mathrm{WBoB}, \mathrm{CBoB})$ is further

491 provided on Figure 10. The largest departures from the seasonal climatology occur in the 492 NBoB box, with in situ anomalies ranging between -1.5 and 1.5 pss (Figure 10a,d). The in 493 situ dataset indicates a freshening anomaly following the 2011 monsoon that lasts until spring 4942012 , followed by a salty anomaly in the 2012 post-monsoon and 2013 monsoon. Aquarius 495 displays a reasonably good phase agreement with the in situ anomalies in this region $(0.75$ 496 correlation; Figure 10d). In particular, it captures the timing of the anomalous freshening from 497 late 2011 to mid-2012 accurately, although its amplitude is twice larger than in observations 498 in late 2011. Aquarius also captures the anomalous saltening observed during the 2013 499 monsoon. In contrast, SMOS exhibits a poor phase agreement with in situ anomalies there 
500 (0.33 correlation; Figure 10a), being unable to capture neither the early 2012 anomalous 501 freshening nor the mid-2013 saltening.

503 to 1 pss. For instance, the freshening along the east Indian coastline following the monsoon is 504 stronger than normal in 2010 and weaker than normal in 2011 and 2012 (Figure 10b,e). Once 505 again, SMOS behaves poorly in this region ( 0.31 correlation; Figure $10 b)$ : it does not 506 reproduce well the fresh event in late 2011 and salty events in late 2012 and 2013, only 507 performing well in late 2013. In contrast, Aquarius SSS estimates display a good phase 508 agreement with the in situ dataset over most of the period ( 0.74 correlation): it is able to 509 capture the abrupt change from salty to fresh anomalies in late 2011, freshening over 2013 510 and salty anomalies in early 2014. It however misses completely the strong saltening signal 511 evident in the in situ dataset in late 2012.

In $\mathrm{CBoB}$, the departures from the seasonal cycle are weaker than in the $\mathrm{NBoB}$ and

513 WBoB boxes, with anomalies that do not exceed 0.5 pss. The in situ SSS displays fresher than 514 normal conditions in early 2012 and most of 2013 and saltier than normal conditions in late 515 2012. As for the two other boxes, Aquarius accurately captures these departures from the 516 seasonal cycle ( 0.77 correlation) while SMOS completely fails ( 0.02 correlation).

As discussed in the previous section, strong departures from the seasonal climatology 519 occur in late 2011 and early 2012 in each of the sub-regions: an anomalous freshening in 520 NBoB from fall 2011 to summer 2012, an anomalous saltening in fall 2011 in WBoB, and an 521 anomalous freshening in spring 2012 followed by a saltening signal in summer 2012 in $522 \mathrm{CBoB}$. The performance of the two satellites in reproducing the spatial patterns related to 523 these seasonal departures from the climatology is illustrated on Figure 11. The in situ product 524 indeed indicates that the northeastern $\mathrm{BoB}$ is fresher than normal in fall 2011, while salty 
525 anomalies are observed to the south of $16^{\circ} \mathrm{N}$ and to the west of $88^{\circ} \mathrm{E}$ (Figure $11 a$ ). The

526 freshening in NBoB expands southward along the east coast of India in winter 2012 (Figure

$52711 b)$ and in the central part of the Bay around $\left(15^{\circ} \mathrm{N} ; 90^{\circ} \mathrm{E}\right)$ in spring 2012 (Figure $11 c$ ).

528 These anomalies in $\mathrm{CBoB}$ reverse sign in summer 2012 (Figure 11d), with two cores of salty 529 anomaly observed around $\left(16^{\circ} \mathrm{N} ; 86^{\circ} \mathrm{E}\right)$ and $\left(10^{\circ} \mathrm{N} ; 88^{\circ} \mathrm{E}\right)$. Aquarius is able to capture the

530 broad spatial structure of the anomalies depicted by the in situ dataset (Figure 11e,h). In 531 contrast, although SMOS captures the NBoB freshening in fall 2011 and winter 2012 (Figure

$53211 i, j)$, it is unable to capture either the saltening along the eastern coast of India in fall 2011, 533 or the amplitude and spatial extend of the freshening in the CBoB in spring 2012 (Figure $53411 k$ ), or the salty anomalies in summer 2012 (Figure $11 l$ ). This example thus illustrates the 535 ability of Aquarius to retrieve regional features in the salinity field within the BoB and the 536 caveats related to SMOS retrieval.

\section{Summary and discussion}

\subsection{Summary}

The BoB exhibits strong meridional and vertical salinity gradients, with very fresh

543 surface waters to the North. The monitoring of SSS variability there is not straightforward due

544 to insufficient in situ data coverage. This monitoring may benefit from the recent availability 545 of SSS remotely-sensed data. The retrieval of satellite-derived SSS measurements is however 546 very challenging in this region, because the semi-enclosed nature of the BoB may potentially 547 contaminate the SSS signals through radio frequency interferences and land effects. The goal 548 of this study is therefore to perform a validation of the SMOS CEC-IFREMER V02 level-3 $5491^{\circ} \times 1^{\circ}$ and Aquarius CAP-V03 level-3 $1^{\circ} \times 1^{\circ}$ gridded monthly salinity retrievals against a comprehensive gridded in situ SSS product in the BoB to infer whether these satellite datasets 
551 can confidently be used to describe SSS variations in this climatically important region. We

552 first estimate that our in situ dataset is reasonably representative of $1^{\circ} \times 1^{\circ}$ monthly SSS

553 estimates. The instrumental error is negligible (approximately $0.01 \mathrm{pss}$ ). The fact that most in

554 situ data are representative of the $5-10 \mathrm{~m}$ depth layer induces a salty bias of up to 0.06 pss

555 and a RMSE of up to 0.2 pss on the surface salinity estimate. The main source of error is the

556 representation error, i.e. the fact that monthly $1^{\circ} \times 1^{\circ}$ SSS estimates are evaluated from a

557 median number of 2 observations per cell, resulting in an estimated RMSE of about 0.3 pss.

558 Collectively, those errors (approximately 0.32 pss RMSE if considered independent) are

559 smaller than the variability in the Bay of Bengal and smaller than the estimated RMSE on

560 individual monthly pixels (around 0.7 pss to $0.9 \mathrm{pss}$ ) from both satellites.

561 Our results reveal large differences in the ability of the SMOS and Aquarius satellite

562 products to retrieve SSS variability. The spatial coverage of the SMOS product is poorer

563 compared to Aquarius, especially in the Northern portion of the BoB. SMOS exhibits a

564 systematic fresh bias everywhere in the Bay of Bengal (-0.19/-0.35 pss depending on the

565 region). In contrast, the mean SSS field retrieved from Aquarius is accurate, except in the

566 northern part of the Bay where it exhibits a -0.26 pss fresh bias. The seasonal variability

567 depicted by Aquarius retrievals is also accurate in the northern, central and western part of the

568 basin with correlations to the reference in situ dataset exceeding 0.9. In contrast, SMOS

569 retrievals fail to represent the SSS seasonal cycle in the western and central part of the basin.

570 Aquarius retrievals are also able to capture departures from the mean seasonal cycle, with a

571 correlation around 0.75 with large-scale year-to-year SSS variations from the in situ dataset in

572 all regions. Aquarius for instance successfully captures the main spatio-temporal features of

573 the anomalous freshening event that occurred in the northern and central part of the BoB in

574 late 2011 and early 2012. In contrast, SMOS estimate generally fails to capture the timing and

575 spatial patterns of SSS departures from the seasonal cycle. 
Figure 12 provides a compelling summary of the added value provided by the two 578 satellite retrievals compared to the existing climatologies. The SMOS retrieval indeed 579 displays a poorer phase agreement with the in situ dataset than the NIOA climatology over the $580 \mathrm{WBoB}$ and $\mathrm{SBoB}$ and a similar agreement over the $\mathrm{NBoB}$ (Figure 12a). In contrast, the 581 situation is far more promising for Aquarius, which exhibits higher correlations with in situ 582 observations than SMOS and NIOA over all the sub-regions (Figure 12b). This indicates that 583 the current version of Aquarius retrievals provide additional information with respect to the existing SSS climatologies in the BoB, while the version of SMOS SSS assessed here does not.

\subsection{Discussion}

588

Preliminary assessments of one-year data from earlier versions of both level-3 SMOS 590 (Subrahmanyam et al. 2013, Ratheesh et al. 2013) and Aquarius datasets (Ratheesh et al. 2014) over the BoB reported major issues in the satellites ability to retrieve SSS there. In this paper, we provide in-depth validations of a more recent version of these level-3 products over 593 a longer period (around 3 years). Our results indicate that the CAP-V03 level- $31^{\circ} \times 1^{\circ}$ gridded

594 monthly Aquarius SSS retrieval performs considerably better than earlier versions, especially 595 for low SSS values in the northern part of the Bay. This better performance could be related to an improved roughness correction in this Aquarius product (Yueh et al. 2014). In contrast, the

597 CEC-IFREMER V02 level-3 $1^{\circ} \times 1^{\circ}$ SMOS retrieval tested here exhibits significant caveats at 598 both seasonal and non-seasonal timescales. This may be partly related to the relaxation to the 599 climatology used in this version of SMOS. Hernandez et al. (2014) actually found better 600 performances for the ESA Level 2 retrieval than for this version in the northern subtropical 
601 Atlantic. As already stated, we however cannot use the ESA level 2 processing because it 602 flags out almost all measurements in the BoB.

603 Subrahmanyam et al. (2013) and Durand et al. (2013) reported errors of the order of 6040.2 pss for SMOS level-3 data in the southern equatorial Indian Ocean. This indicates that the 605 bad performance of SMOS reported in this paper is specific to the BoB. There can be several 606 reasons behind the contrasted ability of SMOS and Aquarius to capture SSS in the BoB. First, 607 the interferometric nature of SMOS instrument makes its measurements much more sensitive 608 to RFIs than a classical radiometer like Aquarius. Second, SMOS is affected by systematic 609 biases extending to about $1000 \mathrm{~km}$ from continents which is until now imperfectly taken into 610 account. Further work is needed to infer if the performance of the SMOS product in the BoB 611 can be improved by updating its algorithm retrieval or of if its performance will anyway be strongly limited by the design of the instruments for this specific region.

616 raises the question of the representativeness of a couple of individual in situ measurements, 617 against the retrieved SSS from satellite, representative of a larger spatial scale (typically $6181^{\circ} \times 1^{\circ} \times 1$ month). The instrumental error is very small $(0.01 \mathrm{pss})$. We did estimate sampling 619 error by taking advantage of the intensive measurements performed at RAMA moorings. The 620 error associated with vertical sampling is generally less than 0.2 pss. The representation error 621 of our in situ reference dataset for monthly $1^{\circ} \times 1^{\circ}$ estimates is generally less than 0.3 pss. If 622 those errors are assumed to be independent, the overall RMSE of our in situ dataset is 623 approximately 0.36 pss. This is far from negligible, but generally smaller than the satellite 624 biases discussed in the present study. In addition, the validation of time series average over 625 larger boxes in typical regions of variability (NBOB, $\mathrm{WBoB}, \mathrm{CBoB}$ ) acts to further reduce 
626 this representation issue. The smallest of the 3 boxes (WBoB) indeed contains up to 40

627 individual $1^{\circ} \times 1^{\circ} \times 1$ month estimates. Even if our reference in situ product provides SSS

628 estimates for only one half of the grid cells (20 measurements), this results in a box-average

629 RMSE inferior to 0.1 pss (when assuming independent errors). While the error statistics of

630 individual satellite data on the $1^{\circ} \times 1^{\circ} \times 1$ month grid should be taken cautiously (i.e. the RMSE

631 is probably enhanced by the representation error), we thus believe that the error statistics for

632 the entire $\mathrm{NBoB}, \mathrm{WBoB}$ and $\mathrm{CBoB}$ boxes provide a more reasonable evaluation of the actual

633 performance of those satellite products. Another caveat is of course the length of the time

634 series (around 3 years). A more in-depth assessment of the capability of the satellites to

635 estimate the seasonal cycle in the $\mathrm{BoB}$ will probably be needed a couple of years down the

636 line, but we believe that the current analysis still clearly points out that, while the current

637 Aquarius large-scale SSS retrieval can be used within the BoB, there is still work to be done 638 to improve existing SMOS retrievals.

639

\section{6.3. Perspectives}

One key-advantage of spaceborne SSS products is their ability to sample regions that

643 are completely devoid of in situ observations. One such region is the Andaman Sea. This

644 region exhibits a large SSS variability in the spaceborne measurements (Figure $2 e, f$ ) and 645 model simulations (Akhil et al. 2014). Like the northern part of the Bay, the Andaman Sea is 646 characterized by intense monsoonal rains (Hoyos and Webster 2007) and continental runoff

647 (Furuichi et al. 2009). Although no in situ SSS observations are available in this region for the 648 recent period, satellites reveal vigorous signals there (Figure 13). Both SMOS and Aquarius 649 indicate a strong seasonal freshening of about 2 pss during the monsoon and post-monsoon 650 seasons, followed by a subsequent saltening in winter-spring. The magnitude of these SSS 651 changes is comparable to those observed in the northern or western part of the BoB (Figure 
652 8). The Andaman Sea post-monsoon freshening depicted by the two satellites is larger than

653 the one suggested by the NIOA climatology. Due to the very limited availability of salinity

654 data in the Andaman sea (Antonov et al. 2010, Chatterjee et al. 2012), and relatively good

655 performance of Aquarius in other regions, one is tempted to believe that it is the NIOA

656 climatology that is erroneous here, and that Aquarius brings us an improved knowledge of the

657 seasonal cycle of SSS in the Andaman Sea. Beyond this seasonal picture, both SMOS and

658 Aquarius data suggest a larger seasonal fresh anomaly during and after the 2012 monsoon

659 than during other years. It would be interesting to assess the quality of the spaceborne SSS

660 products in the Andaman Sea, in order to judge if they can be used for monitoring SSS and

661 understand mechanisms of SSS variability there.

662 It would also be very interesting to better understand the mechanisms driving the

663 interannual SSS variability in the BoB. Using a similar in situ SSS dataset to the one used in

664 this study combined with satellite estimates of rainfall and Ganges-Brahmaputra river runoffs,

665 Chaitanya et al. (2014b) already suggested that interannual SSS variability in the northeastern

666 part of the Bay over the 2009-2012 period was primarily driven by freshwater flux variability,

667 and in particular river runoffs. Given the ability of Aquarius to capture the interannual SSS

668 variations in the $\mathrm{BoB}$ to a reasonable extent, it is very tempting to perform a similar salt

669 budget to the one of Chaitanya et al. (2014b) but using the more spatially complete Aquarius

670 SSS retrieval. Interannual river runoffs data derived from satellite measurements are however

671 only currently available until the end of 2012 (i.e. only 15 months of common data with

672 remotely-sensed SSS) (Papa et al. 2012), so far precluding a meaningful investigation of the

673 interannual mixed-layer salt budget in the BoB. Once interannual runoffs data from the main

674 BoB rivers (i.e. Ganges-Brahmaputra and Irrawaddy) become available for the recent years, a

675 promising follow-up of this work would therefore be to use the Aquarius SSS dataset to 
676 assess the main processes that control the interannual SSS variations in the various regions of 677 the BoB.

678 The present study is dedicated to SMOS and Aquarius salinity assessment. Beyond 679 these two pioneering missions, some evolutions in the field of ocean salinity remote sensing 680 are expected shortly. The next generation of spaceborne sensors usable for SSS monitoring, 681 beginning with Soil Moisture Active and Passive (SMAP) satellite (sucessfully launched in 682 January 2015, see smap.jpl.nasa.gov), promises significant progresses in our ability to retrieve 683 valuable spaceborne estimates of SSS field in the global ocean. We believe our study, focused 684 on one of the most challenging areas of the world ocean, paves the way for the future of 685 spaceborne salinity science there. 


\section{Acknowledgements}

687 This study is supported by the LEFE/EC2CO project GEOMOD (AO2015- 873251) from the 688 French National Institute of Sciences of the Universe (CNRS / INSU). We also acknowledge 689 the financial support by a TOSCA project from CNES, the French Space Agency. AVP was 690 funded through a PhD grant from CNES and IRD. We thank IRD for the financial support for 691 the Indo-French collaboration on Indian Ocean research. In situ SSS samples are collected 692 under support from Ministry of Earth Sciences (Government of India). We are thankful to the 693 numerous people involved in the ARGO and RAMA projects. We sincerely thank the team 694 efforts of technical and scientific staff from National Institute of Ocean Technology, Chennai, 695 India for providing continuous data from the OMNI moorings. Thermosalinograph data were 696 collected and processed by the French SSS Observation Service (www.legos.obs697 mip.fr/observations/sss). CNES partly funded these activities in the frame of the CATDS and 698 of the SMOS TOSCA projects. We acknowledge constructive discussions with Nicolas Reul. 699 We also thank him for sharing the CATDS SMOS level-3 datasets. Clement de Boyer 700 Montegut is supported by the European Union via the seventh Framework Programme 701 (INCO_LAB) GA295092 (INDO-MARECLIM). 


\section{References}

Akhil, V.P., Durand, F., Lengaigne, M., Vialard, J., Keerthi, M. G., Gopalakrishna, V.V., Deltel, C., Papa, F. and de Boyer Montégut,C., 2014, A modeling study of the processes of surface salinity seasonal cycle in the Bay of Bengal. J. Geophys. Res., 116, 39263947, doi : 10.1002/2013JC009632

Alory G., Delcroix, T., Téchiné, P., Diverrès, D., Varillon, D., Cravatte, S., Gouriou, Y., Grelet, J., Jacquin, S., Kestenare, E., Maes, C., Morrow, R., Perrier, J., Reverdin, G., Roubaud, F., 2015, The French contribution to the Voluntary Observing Ships network of Sea Surface Salinity. Deep Sea Research, in press.

Antonov, J. I., Seidov, D., Boyer,T.P., Locarnini, R. A., Mishonov, A.V., Garcia, H. E., Baranova, O. K., Zweng, M.M. and Johnson,D.R., 2010, World Ocean Atlas 2009. Volume 2: Salinity. S. Levitus, Ed. NOAA Atlas NESDIS 69, U.S. Government Printing Office, Washington, D.C., 184 pp.

Benshila, R., Durand, F., Masson S., Bourdalle-Badie, R., de Boyer Montégut, C., Papa, F. and Madec, G., 2014, The upper Bay of Bengal salinity structure in a high-resolution model. Ocean Modelling, 74, 36-52.

Boutin, J., Martin, N., Yin, X., Font, J., Reul, N. and Spurgeon, P., 2012, First assessment of SMOS data over open ocean: part II Sea Surface Salinity. IEEE Transactions on Geoscience and Remote Sensing, doi: 10.1109/TGRS.2012.2184546.

Chaitanya, V.S., Lengaigne, M., Vialard, J., Gopalakrishna, V. V., Durand, F., KranthiKumar, C., Amrithash, S., Suneel, V., Papa, F. and Ravichandran, M., 2014a, Fishermenoperated salinity measurements reveal a "river in the sea" flowing along the east coast of India. BAMS, doi:http://dx.doi.org/10.1175/BAMS-D-12-00243.1

Chaitanya AVS., Durand, F., Mathew, S., Gopalakrishna, V.V., Papa, F., Lengaigne, M., Vialard, J., Krantikumar, C. and Venkatesan, R., 2014b, Observed year-to-year sea 
surface salinity variability in the Bay of Bengal during the period 2009-2014. Ocean Dynamics, doi:10.1007/s10236-014-0802-x.

730 Chakraborty, A., R. Sharma, R. Kumar, and S. Basu (2014), A SEEK filter assimilation of sea surface salinity from Aquarius in an OGCM: Implication for surface dynamics and thermohaline structure, J. Geophys. Res. Oceans, 119, 4777-4796, doi:10.1002/

734

735

736

737

738

739

740

741 2014JC009984.

Chatterjee, A., Shankar, D., Shenoi, S.S.C., Reddy, G.V., Michael, G.S., Ravichandran, M., Gopalkrishna, V.V., Rama Rao, E. P., Udaya Bhaskar, T.V.S. and Sanjeevan, V.N., 2012, A new atlas of temperature and salinity for the north Indian Ocean, J. Earth Syst. Sci., 121(3), 559-593, doi:10.1007/s12040-012-0191-9.

Durand, F., Alory, G., Dussin, R. and Reul, N., 2013, SMOS reveals the signature of Indian Ocean Dipole events. Ocean Dynamics.,63(11-12):1203-1212, doi:10.1007/s10236013-0660-y

Furuichi, T., Win, Z. and Wasson, R.J., 2009, Discharge and suspended sediment transport in the Ayeyarwady River, Myanmar: centennial and decadal changes. Hydrol. Process, 23, 1631-1641.doi: 10.1002/hyp.7295

Gierach, M. M., Vazquez-Cuervo, J., Lee, T. and Tsontos, V.M., 2013, Aquarius and SMOS detect effects of an extreme Mississippi River flooding event in the Gulf of Mexico. Geophys. Res. Lett., 40, 5188-5193, doi:10.1002/grl.50995.

Hareesh Kumar, P. V., Matthew, B., Ramesh Kumar, M. R., Rao, A.R., Jagadesh, P.S.V., Radhakrishnan, K. G. and Shyni, T.N., 2013, 'Thermohaline front' off the east coast of India and its generating mechanism. Oc. Dyn., doi: 10.1007/s10236-013-0652-y

Hasson, A., Delcroix, T., Boutin, J., Dussin, R. and Ballabrera-Poy, J., 2014, Analyzing the 2010-2011 La Niña signature in the tropical Pacific sea surface salinity using in situ 

Research: Oceans, 119, 3855-3867, doi:10.1002/2013JC009388.

754 Hernandez, O., Boutin, J., Kolodziejczyk, N., Reverdin, G., Martin, N., Gaillard, F., Reul, N. and Vergely, J.L., 2014, SMOS salinity in the subtropical north Atlantic salinity maximum: 1. Comparison with Aquarius and in situ salinity. J. Geophys. Res., doi: 10.002/2013JC009610

Hoyos, C.D. and Webster, P.J., 2007, The role of intraseasonal variability in the nature of Asian monsoon precipitation. J. Clim., 20, 4402-4424.

Kerr, Y. H., et al., 2010, The SMOS Mission: New Tool for Monitoring Key Elements of the Global Water Cycle. Proceedings of the IEEE, 98(5), 666-687.

Lagerloef, G., et al., 2008, The Aquarius/SAC-D mission: Designed to meet the salinity remote sensing challenge. Oceanography, 21(1), 68-81 doi:10.5670/oceanog.2008.68.

Lagerloef, G., et al., 2013, Aquarius data release V2.0 validation analysis, Aquarius Proj. 765 Doc. AQ-014-PS-0016. [Available at ftp://podaacftp.jpl.nansa.gov/allData/aquarius/docs/v2/AQ-014-PS-

Locarnini, R.A., Mishonov, A.V., Antonov, J.I., Boyer, T.P., Garcia, H.E., Baranova, O.K., Zweng, M.M. and Johnson, D.R., 2010 World Ocean Atlas, 2009. vol 1. In: Levitus TS (ed) NOAA Atlas NESDIS 68. U.S. Government Printing Office, Washington, DC.

771 McMullan, K. D., Brown, M.A., Martin-Neira, M., Rits, W., Ekholm, S., Marti, J. and Lemanczyk, J., 2008, SMOS: The Payload. IEEE Transactions on Geoscience and Remote Sensing., 46(3), 594-605.

Mecklenburg, S., Kerr, Y., Font, J. and Hahne A., 2008, The Soil Moisture and Ocean Salinity (SMOS) Mission - An overview, Geophysical Research Abstracts, 10. 
776 Mecklenburg, S., Drusch, M., Kerr, Y.H., Font, J., Martin-Neira, M., Delwart, S., Buenadicha, G., Reul, N., Daganzo-Eusebio, E., Oliva, R. and Crapolicchio, R., 2012, ESA’s Soil Moisture and Ocean Salinity Mission: Mission Performance and Operations. IEEE Transactions on Geoscience and Remote Sensing, 50(5), Part 1:1354-1366.

McPhaden, M. J., Meyers, G., Ando, K., Masumoto, T., Murty, V.S.N., Ravichandran, M., Syamsudin, F., Vialard, J., Yu, L. and Yu, W., 2009, RAMA: The Research Moored Array for African-Asian-Australian Monsoon Analysis and Prediction. Bull. Am. Meteorol Soc., 90,459-480.

Menezes, V. V., Vianna, M. L. and Phillips, H.E., 2014, Aquarius sea surface salinity in the South Indian Ocean: Revealing annual-period planetary waves. J. Geophys. Res. : Oceans, 119, 3883-3908, doi:10.1002/2014JC009935.

Neetu, S., Lengaigne, M., Vincent, E. M., Vialard, J., Madec, G., Samson, G., Ramesh Kumar, M.R. and Durand F., 2012, Influence of upper-ocean stratification on tropical cyclone-induced surface cooling in the Bay of Bengal. J. Geophys. Res., 117, C12020, doi: 10.1029/2012JC008433.

Papa, F., Bala, S.K., Pandey, R.K., Durand, F., Gopalakrishna, V.V., Rahman, A. and Rossow, W.B., 2012, Ganga-Brahmaputra river discharge from Jason-2 radar altimetry: an update to the long-term satellite-derived estimates of continental freshwater forcing flux into the Bay of Bengal. J. Geophys. Res. 117, C11021. http://dx.doi.org/10.1029/2012JC008158.

Rao, R. R. and Sivakumar, R., 2003, Seasonal variability of sea surface salinity and salt budget of the mixed layer of the north Indian Ocean. J. Geophys. Res., 108, 3009. doi: 10.1029/2001JC000907. 
Ratheesh, S., Mankad, B., Basu, S., Kumar, R. and Sharma R., 2013, Assessment of SatelliteDerived Sea Surface Salinity in the Indian Ocean. IEEE Geoscience and Remote Sensing Letters 10(3), 428-431, doi 10.1109/LGRS.2012.2207943.

Ratheesh, S., Sharma, R., Sikhakolli, R., Kumar, R. and Basu, S., 2014, Assessing Sea Surface Salinity Derived by Aquarius in the Indian Ocean. IEEE Geoscience and Remote Sensing Letters, 11(4), 719-722.

Reul, N., Tenerelli, J., Boutin, J., Chapron, B., Paul, F., Brion, E., Gaillard, F. and Archer, O., 2012, Overview of the First SMOS Sea Surface Salinity Products. Part I: Quality Assessment for the Second Half of 2010. IEEE Transactions on Geoscience and Remote Sensing, 50(5), Part 1:1636-1647.

Reul, N., Fournier, S., Boutin, J., Hernandez, O., Maes, C., Chapron, B., Alory, G., Quilfen, Y., Tenerelli, J., Morisset, S., Kerr, Y., Mecklenburg, S. and Delwart, S., 2013, Sea Surface Salinity Observations from Space with the SMOS Satellite: A New Means to Monitor the Marine Branch of the Water Cycle. Surv Geophys., doi 10.1007/s10712013-9244-0.

Reul N., Chapron, B., Lee, T., Donlon, C., Boutin, J. and Alory, G., 2014, Sea surface salinity structure of the meandering Gulf Stream revealed by SMOS sensor. Geophys. Res.Lett., 41, 3141-3148, doi:10.1002/2014GL059215.

Roemmich, D., Johnson, G.C., Riser, S., Davis, R., Gilson, J., Owens, W.B., Garzoli, S.L., Schmid, C., Ignaszewski, M., 2009, The Argo Program: Observing the global ocean with profiling floats. Oceanography, 22(2):34-43, doi:10.5670/oceanog.2009.36

Shenoi, S. S. C., Shankar, D. and Shetye, S. R., 2002, Difference in heat budgets of the nearsurface Arabian Sea and Bay of Bengal: Implications for the summer monsoon, $J$. Geophys. Res., 107, 3052, doi: 10.1029/2000JC000679. 
823 Shetye, S. R., Gouveia, A. D., Shankar, D., Michael, G.S. and Nampoothiri, G., 1996,

824

825

826

827

828

829

830

831

832

834

835

836

838

839

840

841

842

843

844

845

846 Hydrography and circulation of the western Bay of Bengal during the Northeast Monsoon. J. Geophys. Res., 101, 14,011 - 14,025.

Subrahmanyam, B., Grunseich, G. and Nyadjro, E.S., 2013, Preliminary SMOS Salinity Measurements and Validation in the Indian Ocean. IEEE Trans. on Geosci. and Remote Sens., vol 51, no. 1,pp. 19-27, jan. 2013.

Tang, W., Yueh, S. H., Fore, A. G., Hayashi, A., Lee, T. and Lagerloef, G., 2014, Uncertainty of Aquarius sea surface salinity retrieved under rainy conditions and its implication on the water cycle study. J. Geophys. Res.: Oceans, 119(8), 4821-4839.

Terray, L., Corre, L., Cravatte, S., Delcroix, T., Reverdin, G. and Ribes, A., 2012, Nearsurface salinity as nature's rain gauge to detect human influence on the tropical water cycle. J. Clim., 25, 958-977, doi:10.1175/JCLI-D-10-05025.1.

Venkatesan, R., Shamji, V. R., Latha, G., Mathew, S., Rao, R. R., Muthiah, A. and Atmanand, M. A., 2013, In situ ocean subsurface time-series measurements from OMNI buoy network in the Bay of Bengal. Current Science (Bangalore), 104(9), 1166-1177.

Vinayachandran, P. N. and Nanjundiah, R.S., 2009, Indian Ocean sea surface salinity variations in a coupled model. Clim. Dyn., doi: 10.1007/s00382-008-0511-6.

Yueh S, Tang, W., Fore, A., Hayashi, A., Song, Y. T. and Lagerloef, G., 2014,Aquarius geophysical model function and combined active passive algorithm for ocean surface salinity and wind retrieval. J. Geophys. Res. Oceans, 119, 5360-5379, doi: 10.1002/2014JC009939.

Zhang, H., Ge Chen., Chengcheng Qian. and Haoyu Jiang., 2013, Assessment of Two SMOS Sea Surface Salinity Level 3 Products Against Argo Upper Salinity Measurements. Geoscience and Remote Sensing Letters, IEEE, 10 (6), 1434-1438. 
847 Zweng, M.M., Reagan, J.R., Antonov, J.I., Locarnini, R.A., Mishonov,A.V., Boyer, T.P., 848 Garcia, H. E., Baranova, O.K., Johnson, D.R., Seidov, D. and Biddle, M.M., 2013, 849 World Ocean Atlas 2013. Volume 2: Salinity. S. Levitus, Ed., A. Mishonov Technical 850 Ed.; NOAA Atlas NESDIS 74, 39 pp. 
853 Figure 1. Climatological Sea Surface Salinity (SSS) in the Bay of Bengal (BoB) from the 854 North Indian Ocean Atlas (NIOA, Chatterjee et al., 2012) for (a) June-July-August (JJA), (b) September-October-November (SON), (c) December-January-February (DJF), and (d) March-April-May (MAM).

Figure 2. Percentage of valid monthly SSS retrievals in the Bay of Bengal for (a) SMOS and (b) Aquarius. Total number of in situ observations profiles per $1^{\circ} \times 1^{\circ}$ box and per year (No. Obs) collocated with $(\boldsymbol{c})$ SMOS and $(\boldsymbol{d})$ Aquarius. Circles on panels $c$ and $d$ indicate RAMA mooring locations, while triangles indicate OMNI moorings. The two continuous lines on panels $c, d$ indicate merchant ships tracks between Port Blair (PB) and Chennai (C) / Kolkata (K), along which approximately 1200 XCTD and bucket measurements were collected. The dotted line indicates the merchant ship track along which thermosalinograph measurements are performed. $(\boldsymbol{e})$ SMOS and $(\boldsymbol{f})$ Aquarius SSS standard deviation. The standard deviation on panels $e_{2} f$ is only shown for pixels with more than 11 months of data. The red boxes on panels $(e)$ and $(f)$ indicate the limits of the $\mathrm{NBoB}\left(86^{\circ} \mathrm{E}-94^{\circ} \mathrm{E} ; 16^{\circ} \mathrm{N}-23^{\circ} \mathrm{N}\right), \mathrm{WBoB}\left(80^{\circ} \mathrm{E}-\right.$ $\left.84^{\circ} \mathrm{E} ; 6^{\circ} \mathrm{N}-16^{\circ} \mathrm{N}\right), \mathrm{CBoB}\left(84^{\circ} \mathrm{E}-94^{\circ} \mathrm{E} ; 6^{\circ} \mathrm{N}-16^{\circ} \mathrm{N}\right)$ and Andaman Sea $\left(94^{\circ} \mathrm{E}-99^{\circ} \mathrm{E} ; 6^{\circ} \mathrm{N}-18^{\circ} \mathrm{N}\right)$, for future reference.

Figure 3. Scatterplots of $1 \mathrm{~m}$ depth versus $10 \mathrm{~m}$ depth daily salinity measurements for the three Bay of Bengal RAMA moorings at (a) $90^{\circ} \mathrm{E} 8^{\circ} \mathrm{N},(\boldsymbol{b}) 90^{\circ} \mathrm{E} 12^{\circ} \mathrm{N}$ and (c) $90^{\circ} \mathrm{E} 15^{\circ} \mathrm{N}$.

Figure 4. (a) Mean correlation coefficient and (b) Root Mean Square Error between monthly average $1 \mathrm{~m}$ depth salinity at the three BoB RAMA moorings and subsampled estimates of the monthly average using from 1 to 15 observations. The statistics were computed from 1000 random subsampling of the monthly data. This plot provides an estimate of the representation error arising from subsampling in our validation in situ SSS dataset.

Figure 5. Scatter plot of (a) SMOS and (b) Aquarius monthly $1^{\circ} \times 1^{\circ} \mathrm{SSS}$ retrievals against collocated estimates from the gridded in situ dataset. The statistics are computed from May 2010 to December 2013 for SMOS and from August 2011 to June 2014 for Aquarius. The corresponding correlation coefficient $(r)$, root-mean square error (RMSE) and bias are 
885 provided on the lower right of each panel. Values in brackets were estimated using only 886 collocated SMOS, Aquarius and in situ data (i.e. the same spatio-temporal sampling is used 887 for both datasets, and the statistics for the two satellites are hence strictly comparable). (c) and $888(d)$ are similar to $(a)$ and $(b)$, but for averaged monthly SSS values over the boxes displayed 889 on Figure $2 e, f$. Blue dots indicate collocated data located in NBOB, green in WBOB and red 890 in CBOB, while black triangles indicate collocated data outside these boxes. The black line 891 indicates median value of each 1pss in situ SSS bin while vertical bars indicate the upper and 892 lower quartiles of the distribution.

893

894 Figure 6. (a) Systematic bias, (b) correlation coefficient and (c) RMSE of box averaged 895 satellite SSS retrievals (SMOS in Bright shade and Aquarius in Light shade) against box896 averaged gridded in situ SSS dataset over each sub-region of the Bay of Bengal.

898 Figure 7. (Upper panels) Climatological Sea Surface Salinity (SSS, pss) in the Bay of 899 Bengal (BoB) for (a) June-July-August (JJA), (b) September-October-November (SON), (c) 900 December-January-February (DJF), and (d) March-April-May (MAM) from NIOA 901 climatology. (Middle panels) Same for SMOS climatological seasonal cycle computed over 902 May 2010 - December 2013 period. (Bottom panels) Same for Aquarius climatological 903 seasonal cycle computed over August 2011- June 2014 period.

904

905 Figure 8. Time series of the SSS climatological seasonal cycle in (a) NBoB, (c) WBoB and 906 (e) $\mathrm{CBoB}$ (outlined on Figure $2 e_{f}$ ) from the gridded in situ product (black line), collocated 907 SMOS retrieval (red line), and box-averaged NIOA climatology (blue line). (b,d,f) Same as $908(a, c, e)$ but for Aquarius retrieval. The correlation coefficient $(r)$ value between in situ and 909 satellite estimates is given on each panel.

911 Figure 9. As in Figure 5 but for SSS anomalies with respect to the mean climatological 912 seasonal cycle from the NIOA climatology.

914 Figure 10. Time series of box-averaged monthly SSS interannual anomalies over the $(\boldsymbol{a})$ $915 \mathrm{NBoB},(\boldsymbol{b}) \mathrm{WBoB}$ and $(\boldsymbol{c}) \mathrm{CBoB}$ from the gridded in situ product (black line) and SMOS 916 retrieval (red line). (d,e,f) Same as $(a, b, c)$ but for Aquarius (red line). The grey shading 917 indicates seasons for which the maps of Figure 11 are plotted. 
919 Figure 11. Mean SSS interannual anomalies for (first column) September to November 920 2011, (second column) December 2011 to February 2012, (third column) March to May

921 2012, (fourth column) and June to August 2012 from (first row) the gridded in situ dataset, 922 (second row) Aquarius and (third row) SMOS.

923

924 Figure 12. (a) Correlation coefficient of SMOS SSS retrieval (coloured bars) and NIOA 925 climatology (coloured frames) against the gridded in situ SSS dataset over each sub-region of 926 the Bay of Bengal. (b) Same as (a) but for Aquarius.

927

928 Figure 13. (a) Box-averaged monthly time series of SSS from SMOS (red) and NIOA 929 climatology (blue) for the Andaman Sea box (framed on Figure 2e,f). (b) Same as (a) but for 930 Aquarius (green). 


\section{$934 \quad$ Figure list}

935

936
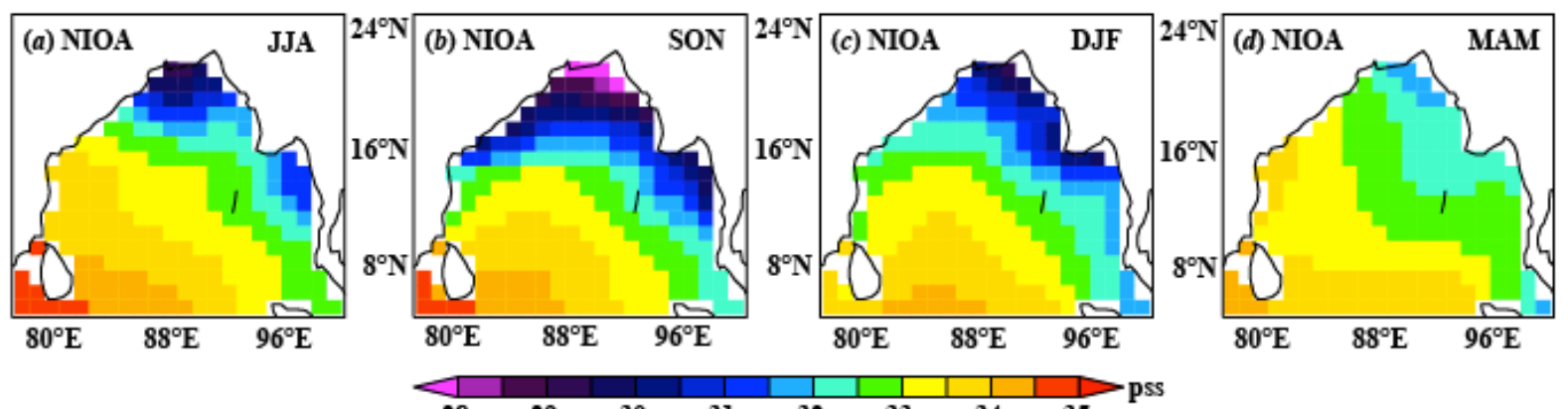

937

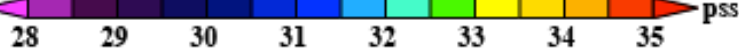

938 Figure 1 

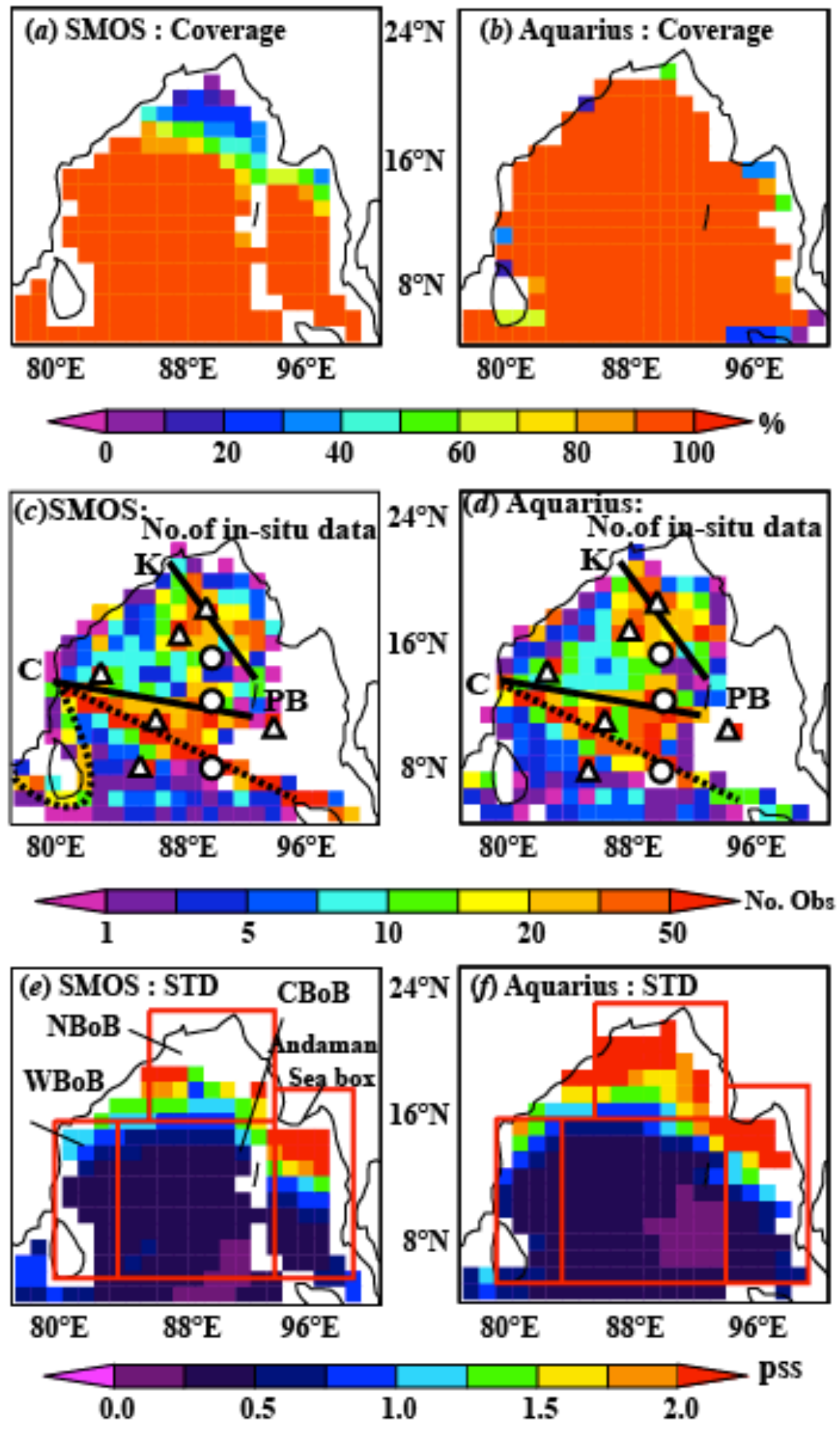

939

$940 \quad$ Figure 2 

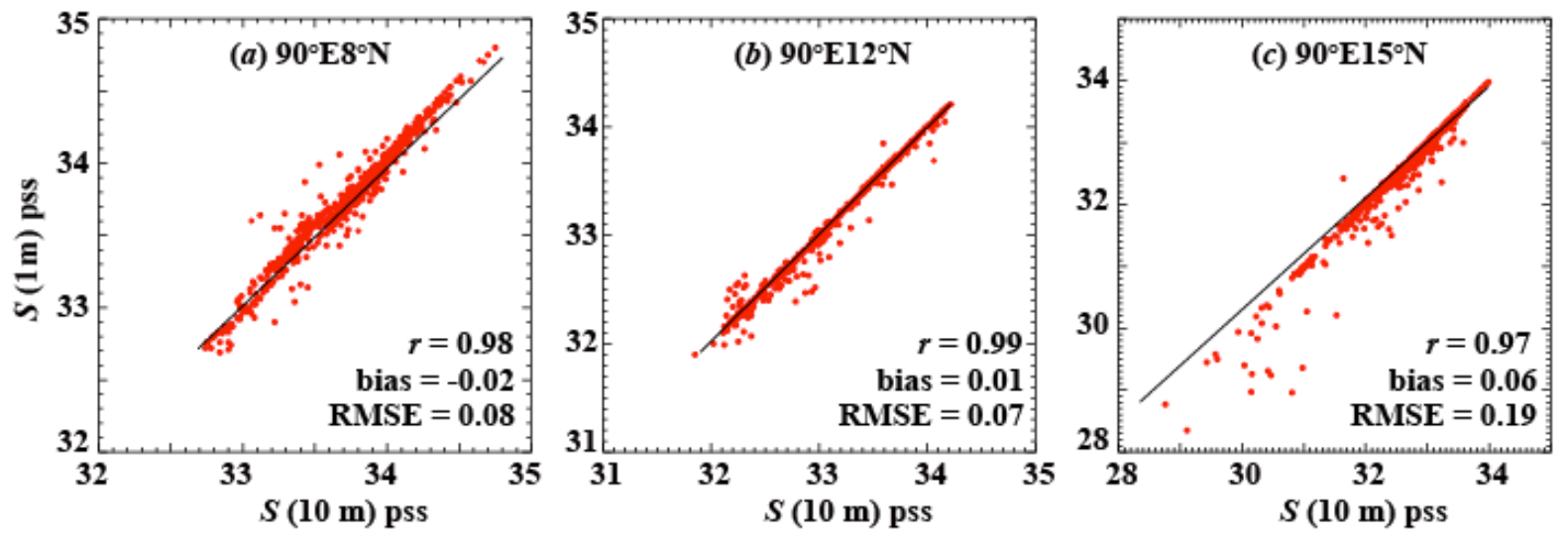

941

942 Figure 3 

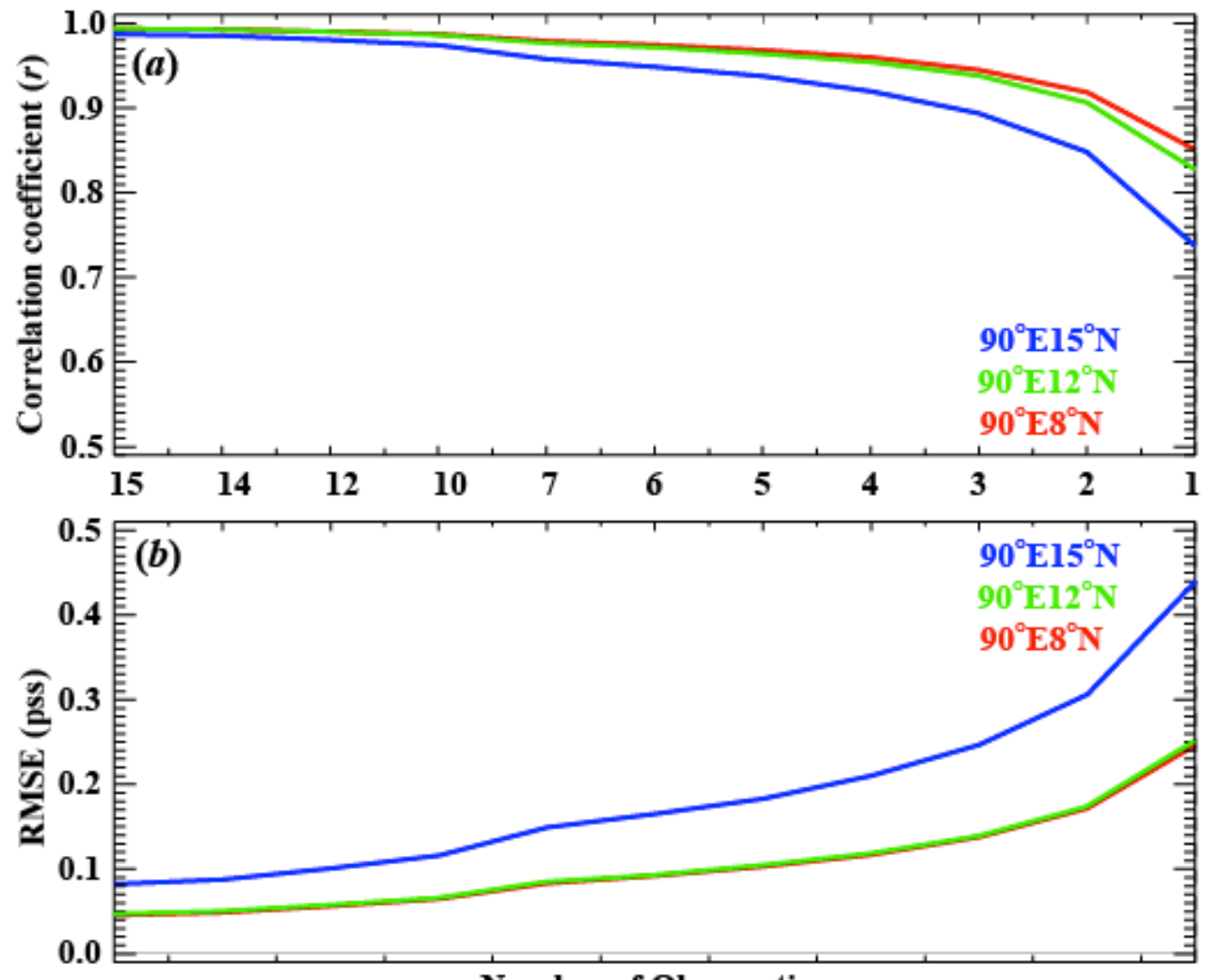

943

Number of Observations

$944 \quad$ Figure 4 

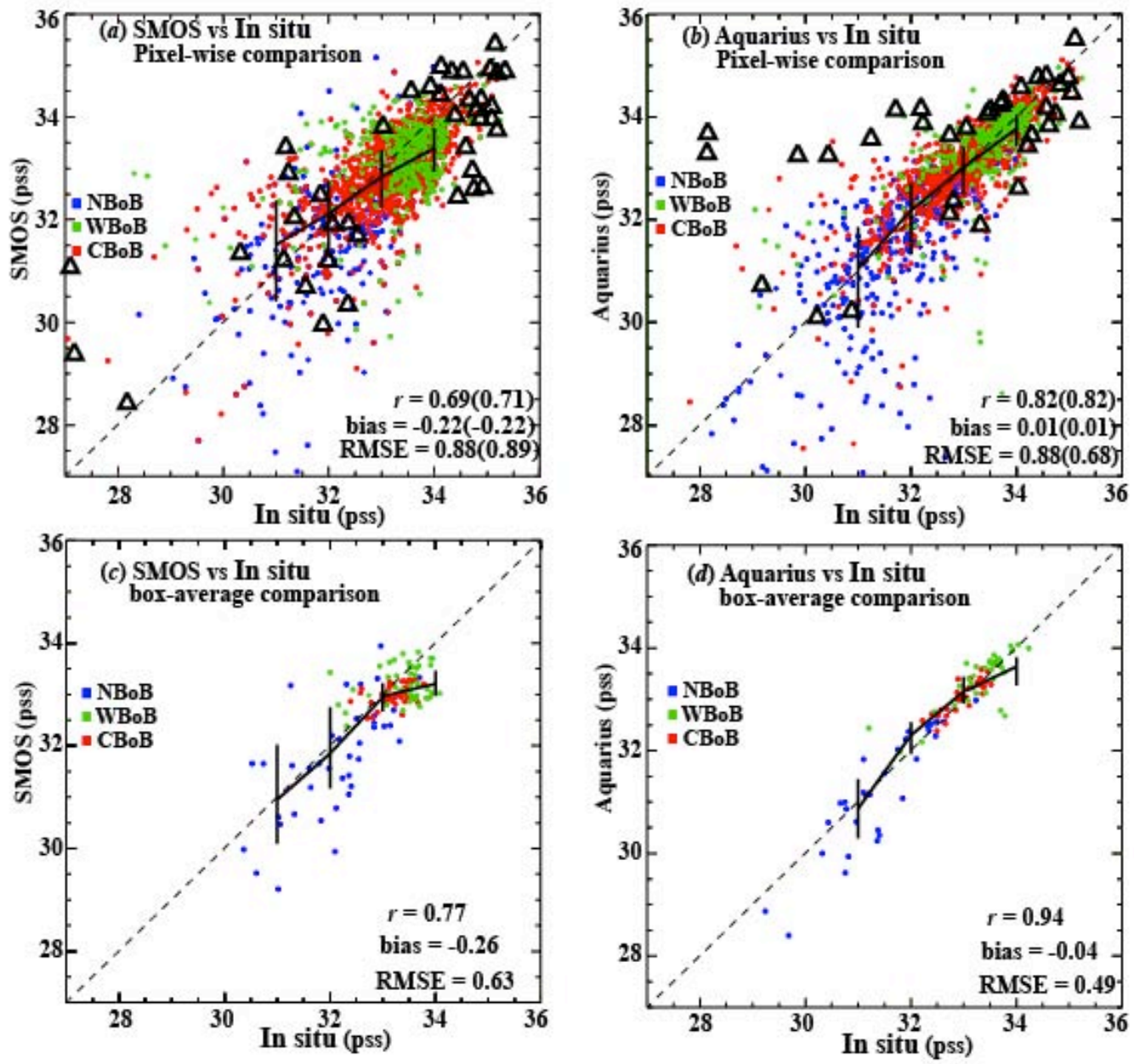

Figure 5 

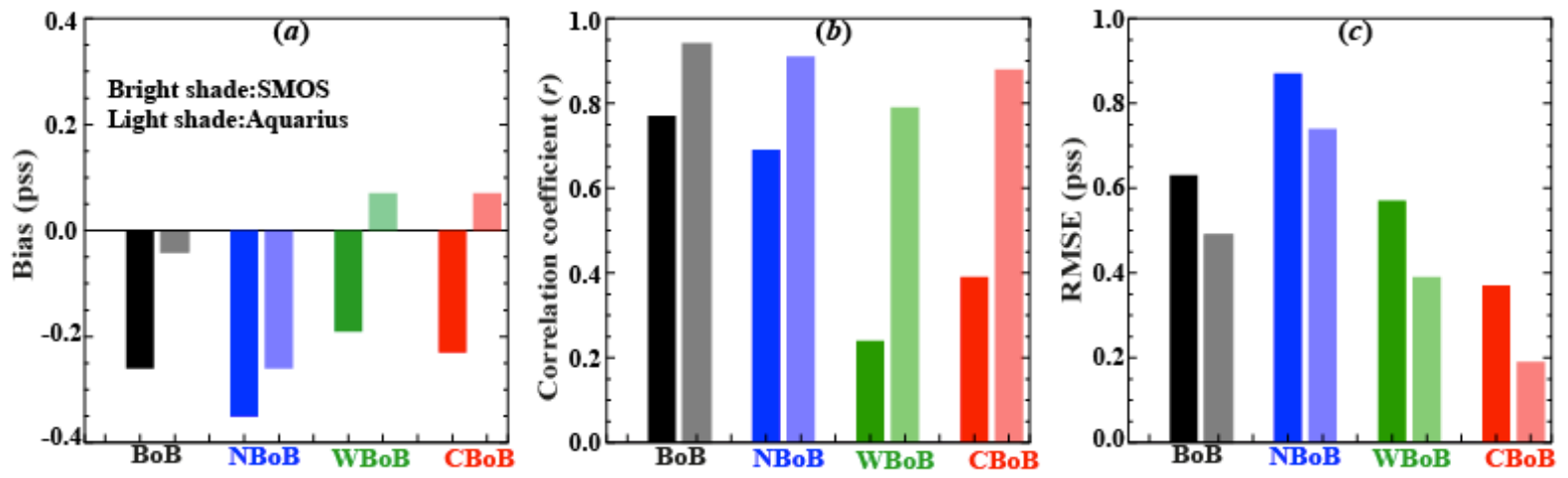

$948 \quad$ Figure 6 

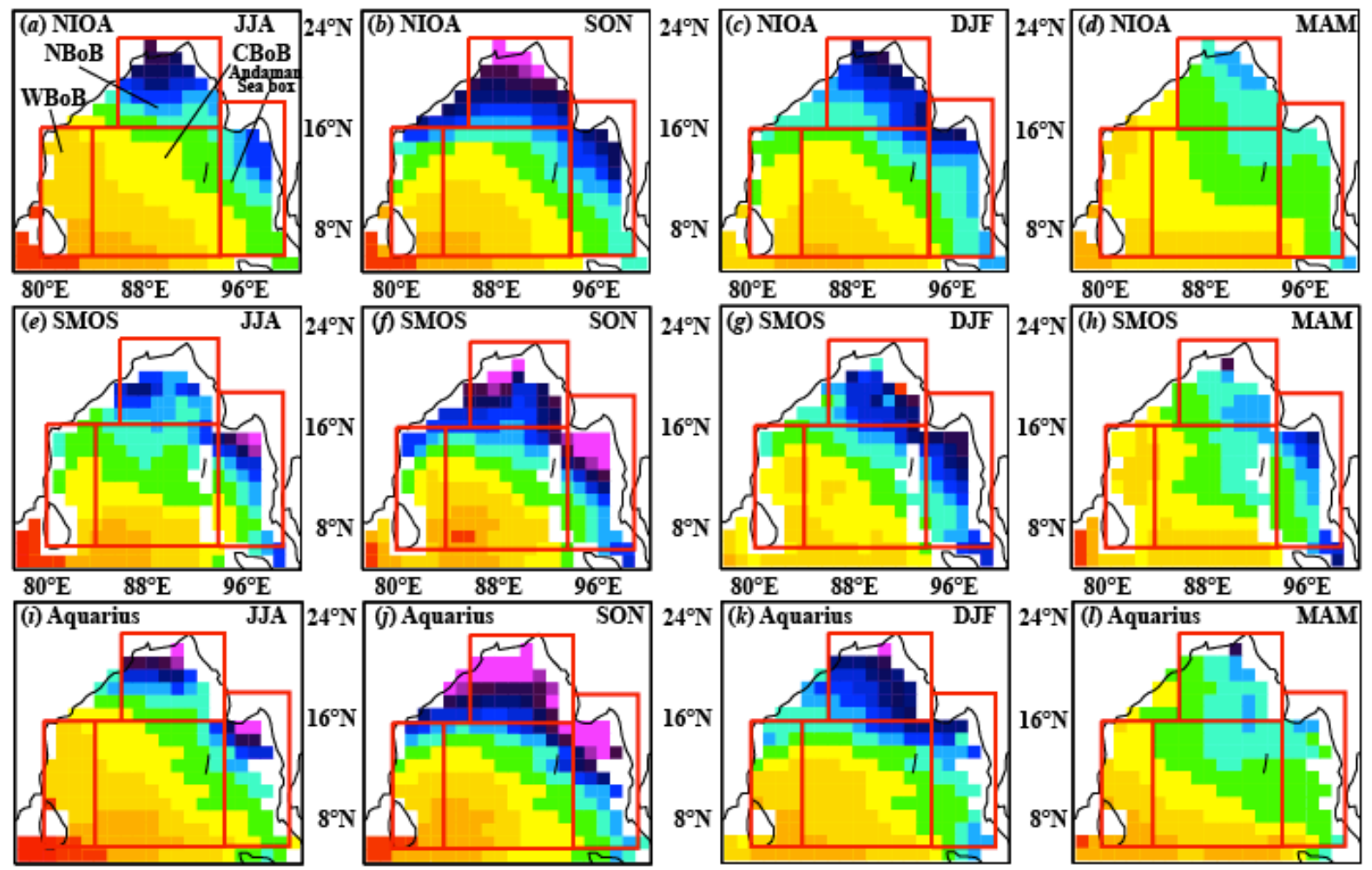

949

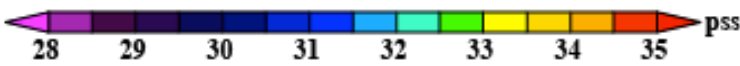

$950 \quad$ Figure 7 

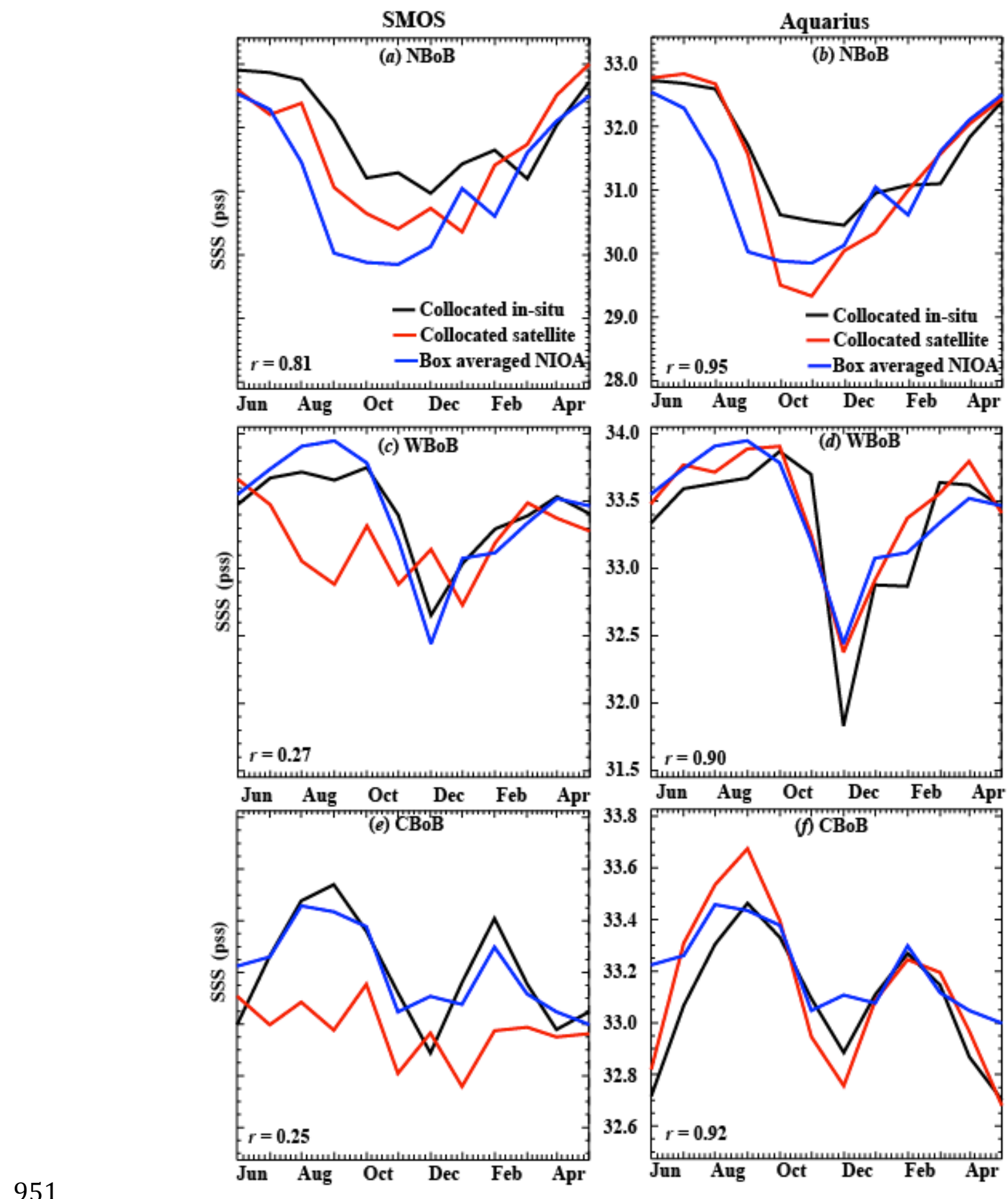

952 Figure 8

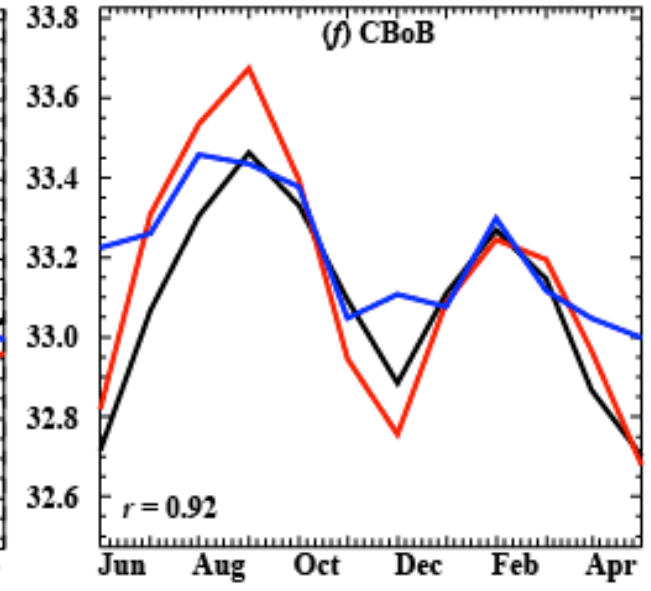



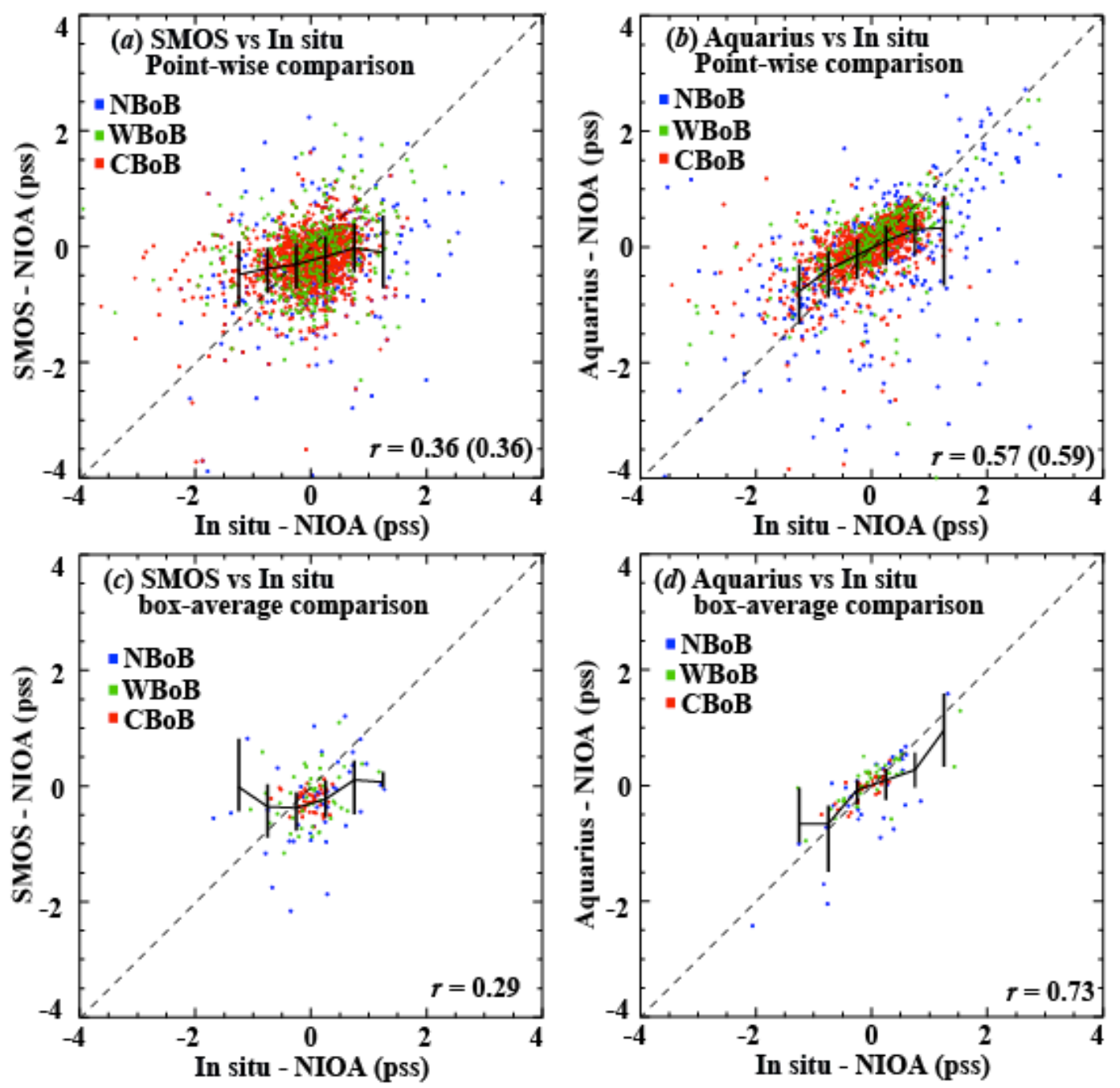

953

$954 \quad$ Figure 9 

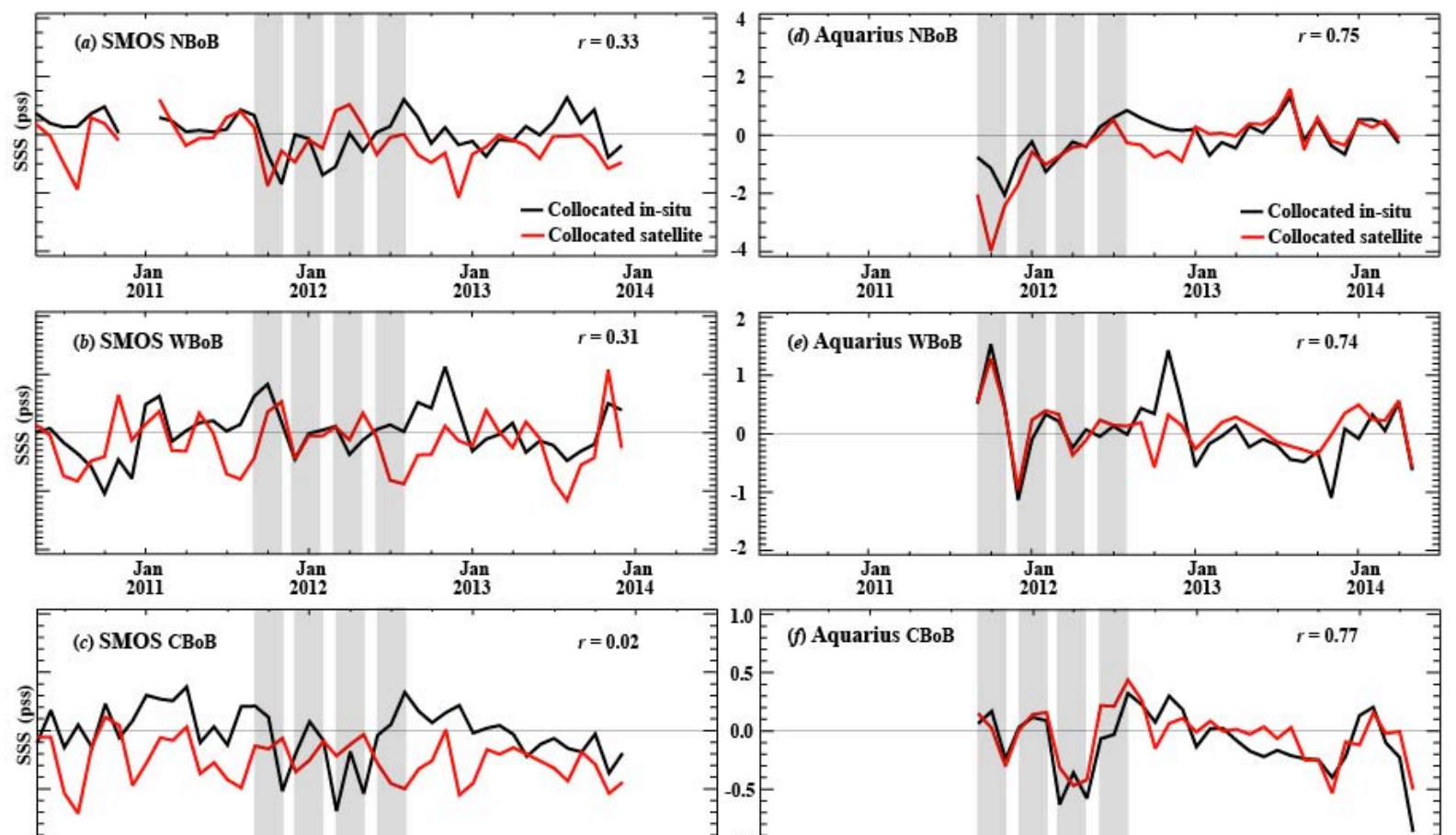

956 Figure 10 


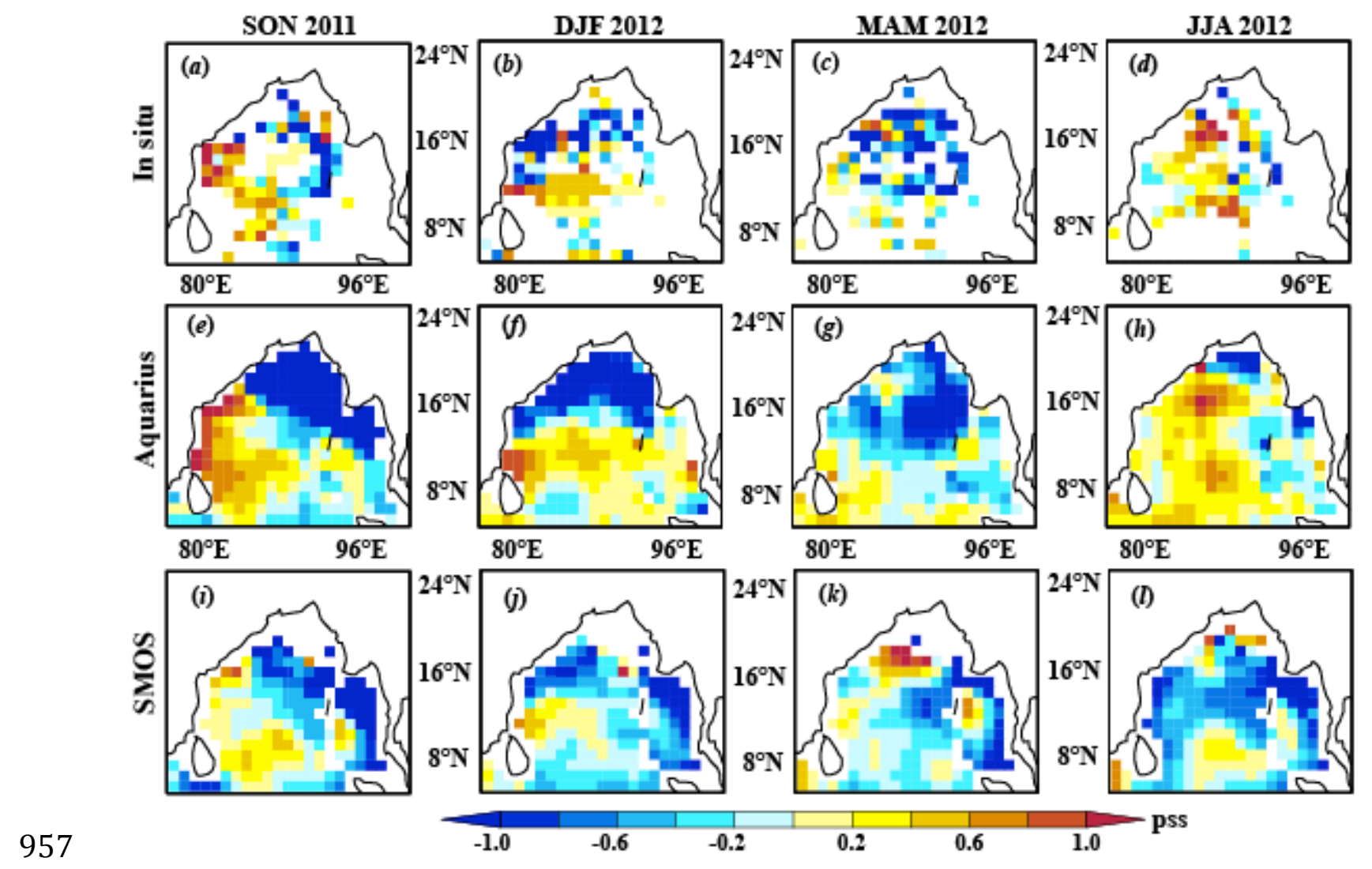

$958 \quad$ Figure 11 


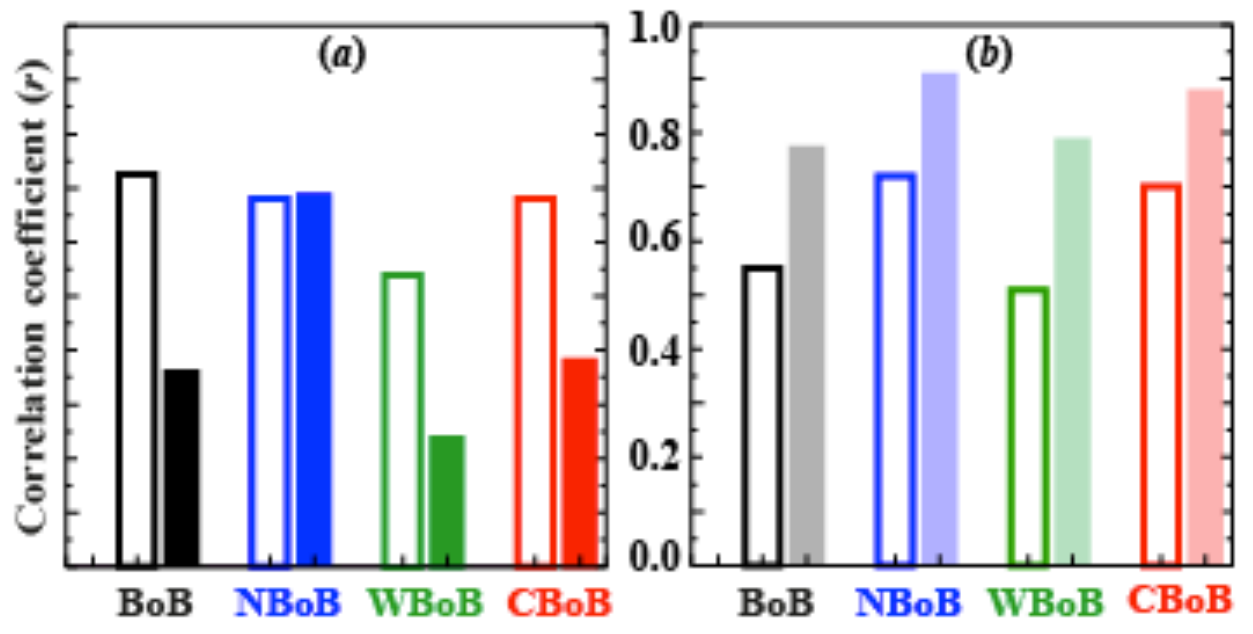

$960 \quad$ Figure 12 

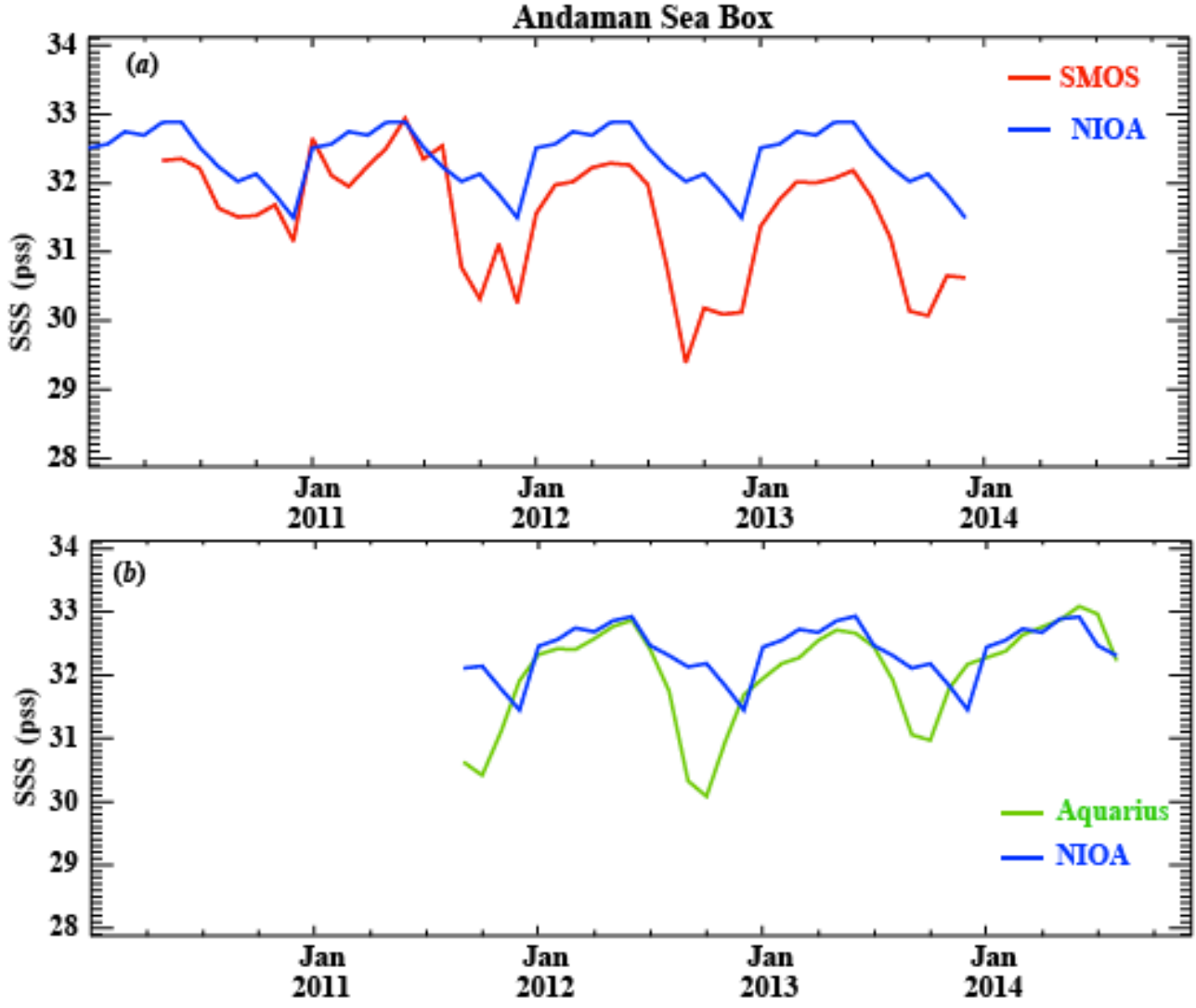

962 Figure 13 